\title{
The Climatic Analysis of Summer Monsoon Extreme Precipitation Events over West Africa in CMIP6 Simulations
}

\author{
Nana Ama Browne Klutse ${ }^{1,2}$ - Kwesi Akumenyi Quagraine ${ }^{3,4} \cdot$ Francis Nkrumah $^{2,4} \cdot$ Kwesi Twentwewa Quagraine $^{5}$. \\ Rebecca Berkoh-Oforiwaa ${ }^{1,2} \cdot$ Joshua Fafanyo Dzrobi ${ }^{1,2} \cdot$ Mouhamadou Bamba Sylla $^{2}$
}

Received: 28 December 2020 / Accepted: 15 January 2021 / Published online: 29 January 2021

(c) The Author(s) 2021

\begin{abstract}
We evaluate the capability of 21 models from the new state-of-the-art Coupled Model Intercomparison Project, Phase 6 (CMIP6) in the representation of present-day precipitation characteristics and extremes along with their statistics in simulating daily precipitation during the West African Monsoon (WAM) period (June-September). The study uses a set of standard extreme precipitation indices as defined by the Expert Team on Climate Change Detection and Indices constructed using CMIP6 models and observational datasets for comparison. Three observations; Global Precipitation Climatology Project (GPCP), Climate Hazards Group InfraRed Precipitation with Station data (CHIRPS), and Tropical Applications of Meteorology using SATellite and ground-based observation (TAMSAT) datasets are used for the validation of the model simulations. The results show that observed datasets present nearly the same spatial pattern but discrepancies in the magnitude of rainfall characteristics. The models show substantial discrepancies in comparison with the observations and among themselves. A number of the models depict the pattern of rainfall intensity as observed but some models overestimate the pattern over the coastal parts (FGOALS-f3-L and GFDL-ESM4) and western part (FGOALS-f3-L) of West Africa. All model simulations explicitly show the pattern of wet days but with large discrepancies in their frequencies. On extreme rainfall, half of the models express more intense extremes in the 95th percentiles while the other half simulate less intense extremes. All the models overestimate the mean maximum wet spell length except FGOALS-f3-L. The spatial patterns of the mean maximum dry spell length show a good general agreement across the different models, and the observations except for four models that show an overestimation in the Sahara subregion. INM-CM4-8 and INM-CM5-0 display smaller discrepancies from their long-term average rainfall characteristics, in terms of extreme rainfall estimates than the other CMIP6 datasets. For the frequency of heavy rainfall, TaiESM1 and IPSL-CMGA-LR perform better when compared with observational datasets. MIROC6 and GFDL-ESM4 displayed the largest error in representing the frequency of heavy rainfall and 95th percentile extremes, and therefore, cannot be reliable. The study has assessed how rainfall extremes are captured in both observation and the models. Though there are some discrepancies, it gives room for improvement of the models in the next version of CMIP.
\end{abstract}

Keywords CMIP6 · Daily precipitation · Rainfall intensity $\cdot$ Extreme precipitation $\cdot$ West African monsoon

Nana Ama Browne Klutse

nklutse@ug.edu.gh

1 Department of Physics, University of Ghana, Accra, Ghana

2 African Institute of Mathematical Sciences (AIMS), Kigali, Rwanda

3 Climate System Analysis Group (CSAG), Department of Environmental and Geographical Science, University of Cape Town, Cape Town, South Africa

4 Department of Physics, University of Cape Coast, Cape Coast, Ghana

5 Department of Physics, Kwame Nkrumah University of Science and Technology, Kumasi, Ghana

\section{Introduction}

Precipitation is one of the most complex climatic variables with extensive impacts on agricultural production, water resource, hydroelectric power generation, and the environment at the local and global scale. As a result of high spatio-temporal changes of precipitation and the influence of complex physical processes (e.g., clouds), it is challenging to predict and mitigate its effects on society. In particular, the extreme precipitation and temperature events have severe socio-economic impacts in terms of their frequency and intensity (Almazroui, 2020a, b). Some studies (e.g., 
Abiodun et al. 2016; Ajibola et al. 2020; Almazroui et al. 2020; James et al. 2018; Klutse et al. 2016a) have used either global climate models (GCMs) and regional climate models (RCMs) to investigate changes in the different attributes of the precipitation such as the frequency, intensity, spatial extent, duration, and timing of these weather and climate events. With growing fluctuations in precipitation regimes, the increasing demand for water due to population growth would be in severe contrast to the low water supply (Smith and Katz, 2013; Trenberth et al. 2014). Understanding the daily precipitation features is thus key for accurate assessments of climate change projections over West Africa for a wide range of decision-makers. For better preparedness and mitigation measures against floods and drought events, there is the need to provide robust information on the variability, occurrence, and distribution of precipitation events. A detailed precipitation monitoring based on various precipitation indices will ensure that quantitative information on precipitation characteristics can be provided to decision and policymakers. However, only a handful of studies (e.g., Akinsanola et al. 2015; Klutse et al. 2016b; Sylla et al. 2013; Sylla, et al. 2016) have focused on the daily precipitation behavior over West Africa.

Given the growing use of GCMs beyond the scientific community for decision-making and impact applications, it is essential to evaluate their performance (Baumberger et al. 2017; James et al. 2015). With the introduction of the new state-of-the-art Coupled Model Intercomparison Project, Phase 6 (CMIP6; Eyring et al. 2016) which is made up of models with higher spatial resolution and additional physical complexity relative to the phase 5 (CMIP5; Taylor et al. 2012) models, it is a useful exercise to assess the performance of CMIP6 models in representing daily summer monsoon rainfall characteristics over West Africa. Other studies (e.g., Akinsanola and Zhou, 2019a, b; Barlow et al. 2019) have opined that these improvements may not necessarily improve model representation of the current climate and precipitation characteristics on regional-scales. It is entirely possible that model performance may vary over regions and across CMIP6 models as differences exist in how they represent physical processes and according to their numerical resolution. Almazroui et al. (2020) projected higher median warming in the CMIP6 model ensemble than CMIP5 over most of Africa but a mixed spatial pattern for precipitation. Earlier studies have also shown evidence of biases in precipitation intensity and frequency in GCMs that have been attributed to limitations in convective parameterization and its subsequent control over precipitation intensity (e.g., Berg et al. 2013; Trenberth, 2011).

Several studies have examined the performance of CMIP3/CMIP5 models in simulating global precipitation characteristics and extremes (e.g., Crétat et al. 2014; Nguyen et al. 2017; Nikiema et al. 2017; Pendergrass \& Hartmann,
2014; Torma et al. 2011; Almazroui and Islam, 2019) and some specific regions (e.g., Akinsanola et al. 2020; Gaetani et al. 2017). However, few studies (e.g., Diallo et al. 2013; Ibrahim et al. 2012; Klutse et al. 2016b, Sylla et al., 2016; Sylla et al. 2013) have focused on examining daily precipitation characteristics over West Africa with other models. This paper seeks to evaluate the capability of CMIP6 models in their representation of the present-day summer monsoon precipitation characteristics and extremes over West Africa. The study uses a set of standard extreme precipitation indices as defined by the Expert Team on Climate Change Detection and Indices (ETCCDI; Tank et al. 2009; Zhang et al. 2011), constructed using CMIP6 models and observational datasets. The following sections describe the data and methods used in our analysis, discussion of the results, and the conclusion of the study.

\section{Data and Methodology}

In this study, we analyze 21 CMIP6 models simulations of daily precipitation datasets (see Table 1) obtained from the Earth System Grid data portal over the West African region bounded by latitudes $4-20^{\circ} \mathrm{N}$ and longitudes $17^{\circ} \mathrm{W}-17^{\circ} \mathrm{E}$ (Fig. 1).

To assess the ability of the different CMIP6 models in simulating the daily characteristics of precipitation, multiple gridded daily precipitation datasets that are frequently used as reference datasets in climate research were used for the period of 1997-2014. This time period is common across the observation dataset and the historical run of the CMIP6 experiment. Three gridded observational datasets are used: the Global Precipitation Climatology Project OneDegree Daily product (GPCP 1DD Version 1.2; Huffman and Bolvin, 2013), the Climate Hazards Group InfraRed Precipitation with Station data (CHIRPS; Funk et al. 2015) and is available from 1981 to present at a $0.5^{\circ} \times 0.5^{\circ}$ resolution and the Tropical Applications of Meteorology using SATellite and ground-based observation (TAMSAT; Maidment et al. 2017) at a $0.035^{\circ} \times 0.035^{\circ}$ resolution. To directly compare the extreme precipitation metrics from the multimodel summary statistics, all datasets were regridded to a common $2.8^{\circ} \times 2.8^{\circ}$ (lat $\times$ lon) grid using bilinear remapping algorithm from the Climate Data Operators (https://code. zmaw.de/projects/cdo). This relatively coarse resolution roughly matches the grid of the simulations with the lowest resolution.

Our analysis considers the West African Monsoon summer season (June-September: JJAS). The mean precipitation over West Africa is examined briefly, thereafter, we focused on different hydroclimatic indices (as shown in Table 2) (Tank et al. 2009; Zhang et al. 2011) as a proxy to assessing the daily rainfall characteristics (simple daily intensity index, frequency 
Table 1 Details of the 21 CMIP6 models used in this study

\begin{tabular}{|c|c|c|c|c|}
\hline No. & Model & Institute & $\begin{array}{l}\text { Horizontal reso- } \\
\text { lution (lon. } \times \\
\text { lat.) }\end{array}$ & References \\
\hline 1 & MPI-ESM-1-2-LR & Max Planck Institute for Meteorology, Germany & $1.9^{\circ} \times 1.9^{\circ}$ & Mauritsen et al. (2019) \\
\hline 2 & MPI-ESM-1-2-h & Max Planck Institute for Meteorology, Germany & $0.9^{\circ} \times 0.9^{\circ}$ & Gutjahr et al. (2019) \\
\hline 3 & CanESM5 & Canadian Earth System Model, Canada & $2.8^{\circ} \times 2.8^{\circ}$ & Swart et al. (2019) \\
\hline 4 & BCC-ESM1 & $\begin{array}{l}\text { Beijing Climate Centre (BCC) and China Meteorological Administration } \\
\text { (CMA), China }\end{array}$ & $2.8^{\circ} \times 2.8^{\circ}$ & Zhang et al. (2019) \\
\hline 5 & INM-CM5-0 & Institute for Numerical Mathematics, Russia & $2.0^{\circ} \times 1.5^{\circ}$ & Volodin et al. (2018) \\
\hline 6 & KACE-1-0-G & $\begin{array}{l}\text { National Institute of Meteorological Sciences, Korea Meteorological } \\
\text { Administration, Republic of Korea }\end{array}$ & $1.9^{\circ} \times 1.3^{\circ}$ & Byun et al. (2019) \\
\hline 7 & FGOALS-f3-L & $\begin{array}{l}\text { LASG, Institute of Atmospheric Physics, Chinese Academy of Sciences } \\
\text { and CESS, Tsinghua University, China }\end{array}$ & $1.3^{\circ} \times 1.0^{\circ}$ & He et al. (2019) \\
\hline 8 & BCC-CSM2-MR & $\begin{array}{l}\text { Beijing Climate Centre (BCC) and China Meteorological Administration } \\
\text { (CMA), China }\end{array}$ & $1.1^{\circ} \times 1.1^{\circ}$ & Wu et al. (2019) \\
\hline 9 & IPSL-CM6A-LR & Institute Pierre-Simon Laplace (IPSL), France & $2.5^{\circ} \times 1.3^{\circ}$ & Boucher et al. (2020) \\
\hline 10 & TaiESM1 & Research Centre for Environmental Changes (AS-RCEC), Taiwan & $0.9^{\circ} \times 1.3^{\circ}$ & Lee et al. (2020) \\
\hline 11 & MRI-ESM-2-0 & Meteorological Research Institute (MRI), Japan & $1.1^{\circ} \times 1.1^{\circ}$ & Yukimoto et al. (2019) \\
\hline 12 & NorESM2-MM & Norwegian Climate Centre, Norway & $1.3^{\circ} \times 0.9^{\circ}$ & Seland et al. (2020) \\
\hline 13 & MIROC6 & $\begin{array}{l}\text { Japan Agency for Marine-Earth Science and Technology, Atmosphere } \\
\text { and Ocean Research Institute (The University of Tokyo), and National } \\
\text { Institute for Environmental Studies, Japan }\end{array}$ & $1.4^{\circ} \times 1.4^{\circ}$ & Tatebe et al. (2019) \\
\hline 14 & ACCESS-CM2 & $\begin{array}{l}\text { Commonwealth Scientific and Industrial Research Organisation-Aus- } \\
\text { tralia Bureau of Meteorology (BoM), Australia }\end{array}$ & $1.9^{\circ} \times 1.3^{\circ}$ & Bi et al. (2012) \\
\hline 15 & INM-CM4-8 & Institute for Numerical Mathematics, Russia & $2.0^{\circ} \times 1.5^{\circ}$ & Volodin et al. (2018) \\
\hline 16 & SAM0-UNICON & $\begin{array}{l}\text { Seoul National University Atmosphere Model Version } 0 \text { with a Unified } \\
\text { Convection Scheme, South Korea }\end{array}$ & $1.2^{\circ} \times 0.9^{\circ}$ & Park and Shin, (2019) \\
\hline 17 & NESM3 & Nanjing University of Information Science and Technology, China & $1.9^{\circ} \times 1.9^{\circ}$ & Cao et al. (2018) \\
\hline 18 & ACCESS-ESM1-5 & $\begin{array}{l}\text { Commonwealth Scientific and Industrial Research Organisation, Aus- } \\
\text { tralia }\end{array}$ & $1.9^{\circ} \times 1.2^{\circ}$ & Law et al. (2017) \\
\hline 19 & FGOALS-g3 & $\begin{array}{l}\text { LASG, Institute of Atmospheric Physics, Chinese Academy of Sciences } \\
\text { and CESS, Tsinghua University, China }\end{array}$ & $2.0^{\circ} \times 2.3^{\circ}$ & Pu et al. (2020) \\
\hline 20 & MPI-ESM-1-2-HAM & Max Planck Institute for Meteorology, Germany & $1.9^{\circ} \times 1.9^{\circ}$ & Tegen et al. (2019) \\
\hline 21 & GFDL-ESM4 & Geophysical Fluid Dynamics Laboratory (GFDL), USA & $1.3^{\circ} \times 1.0^{\circ}$ & Held et al. (2019) \\
\hline
\end{tabular}

of wet days and heavy rainfall events, extreme precipitation events represented as the 95th percentile, and maximum wet spell and dry spell length). These hydroclimatic indices selected have been used in many studies (e.g., Klutse et al. 2016a, b; Akinsanola et al. 2019b) and are useful analysis when seeking to understand the daily rainfall variability over any given region. In the study, a rainfall event is defined as a day with a minimum precipitation amount exceeding $1 \mathrm{~mm}$ (e.g., Akinsanola et al. 2020). Supplementary analyses on the performance of CMIP6 simulations investigated are the root mean squared error (RMSE) and the relative standard deviation (RSD). RMSE indicates the error of a model in predicting quantitative data based on how concentrated the model data is around the line of best fit. RSD is used to determine if the standard deviation of a set of data is small or large when compared to the mean. In other words, the RSD shows how precise the average of your results is. The higher the RSD, the more spread out the results are from the mean of the data. These quantitative measures are done by considering only the grid points over the land for all the indices defined in Table 2. It is worth mentioning that for this examination, only GPCP is utilized in the spatial distribution to have an immediate idea regarding the spatial patterns; notwithstanding, for the quantitative measures of model performance (Tables 3, 4, 5, and 6), all observation dataset (GPCP, CHIRPS, and TAMSAT) are employed to account for uncertainties in the observed daily precipitation products. 


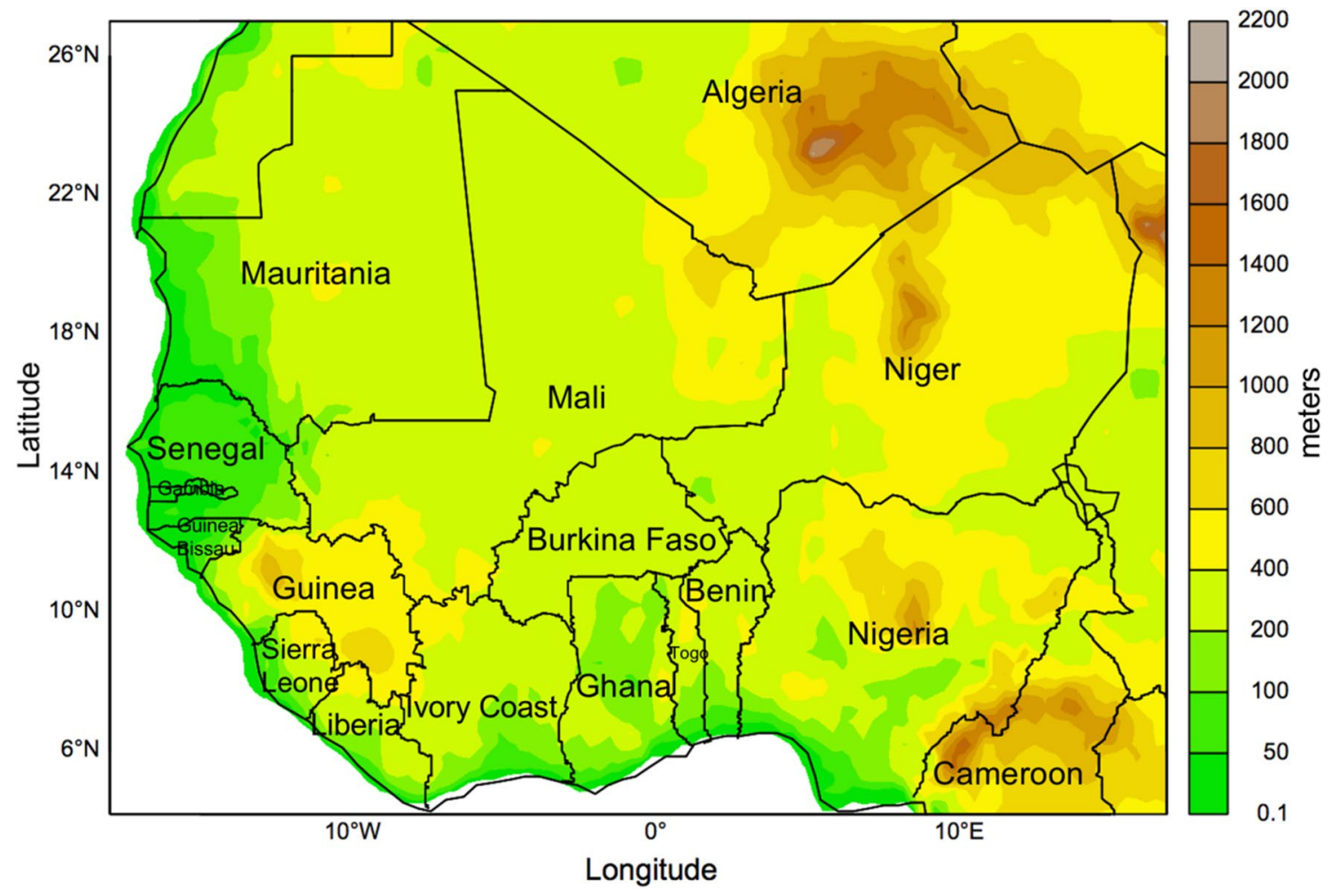

Fig. 1 West African region and topography (in meters) with dark brown areas showing highlands

Table 2 Selected indices used in this study and their definition

\begin{tabular}{ll}
\hline Indices & Definitions \\
\hline Simple daily intensity index & Precipitation intensity exclusively due to wet days \\
Number of wet days & Maximum number of days with precipitation $>1 \mathrm{~mm}$ \\
Frequency of heavy rainfall events & Maximum number of days with precipitation $>20 \mathrm{~mm}$ \\
Extreme rainfall at 95 th percentile & Only $5 \%$ of the data are above this value \\
Mean maximum wet spell length & Maximum number of consecutive wet days \\
Mean maximum dry spell length & Maximum number of consecutive dry days \\
\hline
\end{tabular}

\section{Results and Discussion}

\subsection{Rainfall Climatology}

To better understand the discrepancies between GCMs and observed records of rainfall over West Africa, we assess the spatial pattern of the climatology of the summer monsoon (JJAS) season. The spatial distribution of the mean JJAS rainfall climatology (Fig. 2) for observations (GPCP, CHIRPS, and TAMSAT) and the 21 CMIP6 datasets shows that all CMIP6 GCMs (except FGOALSg3) are able to capture the general rainfall pattern of the region and further, show the position of the ITCZ which is located approximately $10^{\circ} \mathrm{N}$. The observational datasets present approximately the same spatial pattern of rainfall climatology, but the simulations present some discrepancies relative to the observations and among the models. For example, ACCESS-CM2, KACE-1-0-G, INM-CM4-8, and FGOALS-g3 underestimate the amount of daily rainfall over West Africa with KACE-1-0-G specifically showing lower mean monsoon rainfall values over the Guinea Coast. GFDL-ESM4, CanESMS, and MIROC6 overestimate mean monsoon rainfall with CanESMS presenting an overestimation in the highlands of Cameroon mountains, Sierra Leone coast, and the Guinea mountains. MIROC6 overestimates the mean monsoon rainfall from central Nigeria through to the Sierra Leonean coast and the GFDL-ESM4 shows an overestimation across the whole region even though it is able to represent the expected rainfall climatology pattern spatially. 
Table 3 Root Mean Square Error (RMSE) between simulated precipitation intensity and that of the observations (GPCP, CHIRPS, and TAMSAT)

\begin{tabular}{llll}
\hline Models & GPCP & CHIRPS & TAMSAT \\
\hline MPI-ESM1-2-LR & 0.51 & 0.62 & 1.47 \\
MPI-ESM1-2-HR & 0.50 & 0.45 & 2.06 \\
CanESM5 & 1.45 & 1.24 & 3.09 \\
BCC-ESM1 & 1.01 & 0.87 & 2.56 \\
INM-CM5-0 & 2.81 & 2.61 & 4.48 \\
KACE-1-0-G & 1.85 & 1.64 & 3.51 \\
FGOALS-f3-L & 3.79 & 4.02 & 2.48 \\
BCC-CSM2-MR & 0.95 & 0.78 & 2.55 \\
IPSL-CMGA-LR & 1.28 & 1.06 & 2.90 \\
TAiESM1 & 1.46 & 1.25 & 3.07 \\
MRI-ESM2-0 & 1.84 & 1.64 & 3.48 \\
NORESM2-MM & 0.77 & 0.71 & 2.24 \\
MIROC6 & 0.86 & 0.72 & 2.33 \\
ACCESS-CM2 & 2.02 & 1.81 & 3.69 \\
INM-CM4-8 & 2.95 & 2.74 & 4.61 \\
SAMO-UNICON & 1.51 & 1.67 & 0.81 \\
NESM3 & 0.79 & 0.99 & 1.07 \\
ACCESS-ESM1-5 & 1.55 & 1.32 & 3.11 \\
FGOALS-g3 & 2.98 & 2.78 & 4.65 \\
MPI-ESM-1-1-HAM & 0.60 & 0.64 & 1.51 \\
GFDL-ESM4 & 1.98 & 2.13 & 0.77 \\
\hline
\end{tabular}

\subsection{Rainfall Intensity}

The mean intensity of daily rainfall events is calculated and presented in Fig. 3 for the three-observation dataset and CMIP6 GCMs. Table 3 encapsulates the root mean squared error (RMSE) between the models and observed rainfall intensities from GPCP, CHIRPS, and TAMSAT determined for the West African region. The underestimation of some CMIP6 models and the overestimation of others lead to variations in RMSE over the region. The RMSEs turn to be higher generally when the models are compared with TAMSAT since this observation dataset tends to produce more intense rainfall.

GPCP shows higher mean daily rainfall intensities in Guinea-Sierra Leone region which further spreads to Nigeria with decreasing mean daily rainfall intensities. In the Sahel regions, mean intensities of daily rainfall are lower as compared to the coastal regions. Concerning GPCP, CanESM5, BCC-ESM1, NESM3, MIROC6, and MPI-ESM1-2-HAM are well able to capture the pattern of rainfall intensities over southern West Africa. These patterns are captured at different rainfall intensity levels in all aforementioned models. The CanESM5, MIROC6, and MPI-ESM1-2-HAM simulations show a lower rainfall intensity as compared to the GPCP in the Sahel region. INM-CM5-0,
Table 4 Root Mean Square Error (RMSE) between simulated frequency of heavy rainfall and that of the observations (GPCP, CHIRPS, and TAMSAT)

\begin{tabular}{llll}
\hline Models & GPCP & CHIRPS & TAMSAT \\
\hline MPI-ESM1-2-LR & 2.44 & 3.71 & 3.40 \\
MPI-ESM1-2-HR & 1.63 & 2.95 & 2.65 \\
CanESM5 & 1.71 & 3.15 & 2.87 \\
BCC-ESM1 & 2.81 & 4.24 & 3.94 \\
INM-CM5-0 & 2.40 & 0.89 & 1.14 \\
KACE-1-0-G & 0.95 & 2.11 & 1.83 \\
FGOALS-f3-L & 3.43 & 4.89 & 4.60 \\
BCC-CSM2-MR & 0.93 & 1.13 & 0.90 \\
IPSL-CMGA-LR & 1.65 & 0.86 & 0.83 \\
TAiESM1 & 0.85 & 1.57 & 1.30 \\
MRI-ESM2-0 & 1.00 & 1.77 & 1.52 \\
NORESM2-MM & 2.38 & 3.88 & 3.59 \\
MIROC6 & 5.13 & 6.61 & 6.31 \\
ACCESS-CM2 & 1.22 & 2.51 & 2.24 \\
INM-CM4-8 & 2.61 & 1.03 & 1.32 \\
SAMO-UNICON & 4.01 & 5.45 & 5.17 \\
NESM3 & 3.42 & 4.93 & 4.62 \\
ACCESS-ESM1-5 & 1.97 & 3.14 & 2.85 \\
FGOALS-g3 & 1.14 & 1.12 & 0.94 \\
MPI-ESM-1-1-HAM & 3.18 & 4.62 & 4.32 \\
GFDL-ESM4 & 4.68 & 6.20 & 5.89 \\
\hline
\end{tabular}

KACE-1-0-G, TaiESM1, MRI-ESM2-0, ACCESS-CM2, FGOALS-g3, and INM-CM4-8 show lower intensities over the region and thus, underestimate the pattern observed in GPCP. This is evident in the high RMSEs recorded by the aforementioned models when compared to GPCP (Table 3). FGOALS-f3-L and GFDL-ESM4 which also record relatively high RMSEs are marked by their overestimation of the observational dataset. Similar behavior in RMSE is observed also in CHIRPS, depicting similar errors in CMIP6 datasets against both GPCP and CHIRPS. This is different in the case of TAMSAT. For instance, according to the distribution of RMSE, it is realized that MPI-ESM1-2-h gives out the best presentation with $0.50 \mathrm{~mm} /$ day and $0.45 \mathrm{~mm} /$ day while FGOALS-f3-L prediction shows the largest error of $3.79 \mathrm{~mm} /$ day and $4.02 \mathrm{~mm} /$ day as against both GPCP and CHIRPS, respectively. On the other hand, GFDL-ESM4 was found as the best model for predicting accurate rainfall intensity, while FGOALS-g3 shows the largest error when compared with TAMSAT. A common feature associated with the GCMs is the underestimation of daily rainfall intensities in the Sahel regions. Despite the disparities in intensities, it is observed that the majority of the GCMs depict the general pattern as represented by the observations. The difficulty in simulating accurately monsoon rainfall intensities is consistent with previous studies using CMIP Phase 5 models (e.g., 
Table 5 Root Mean Square Error (RMSE) between simulated extreme precipitation at 95th percentile and that of the observations (GPCP, CHIRPS, and TAMSAT)

\begin{tabular}{lrrr}
\hline Models & GPCP & CHIRPS & TAMSAT \\
\hline MPI-ESM1-2-LR & 3.79 & 4.15 & 2.88 \\
MPI-ESM1-2-HR & 3.59 & 3.94 & 2.67 \\
CanESM5 & 8.59 & 8.99 & 7.66 \\
BCC-ESM1 & 9.83 & 10.23 & 8.89 \\
INM-CM5-0 & 1.20 & 1.11 & 1.41 \\
KACE-1-0-G & 3.26 & 3.63 & 2.41 \\
FGOALS-f3-L & 10.57 & 10.96 & 9.61 \\
BCC-CSM2-MR & 4.56 & 4.94 & 3.68 \\
IPSL-CMGA-LR & 4.89 & 5.25 & 4.03 \\
TAiESM1 & 2.64 & 2.99 & 1.83 \\
MRI-ESM2-0 & 2.47 & 2.65 & 1.62 \\
NORESM2-MM & 5.62 & 6.08 & 4.79 \\
MIROC6 & 12.55 & 12.98 & 11.64 \\
ACCESS-CM2 & 2.11 & 2.46 & 1.26 \\
INM-CM4-8 & 1.19 & 0.89 & 1.83 \\
SAMO-UNICON & 8.99 & 9.36 & 8.02 \\
NESM3 & 5.69 & 6.13 & 4.76 \\
ACCESS-ESM1-5 & 3.89 & 4.17 & 2.93 \\
FGOALS-g3 & 2.17 & 2.41 & 1.70 \\
MPI-ESM-1-1-HAM & 6.25 & 6.64 & 5.31 \\
GFDL-ESM4 & 16.18 & 16.58 & 15.23 \\
\hline
\end{tabular}

Akinsanola and Zhou 2019a) and seems persistent with the new state-of-the-art CMIP6 models.

\subsection{Frequency of Wet Days}

The mean frequency of wet days expressed as a percentage of the total annual days is calculated and shown in Fig. 4. The observations show approximately similar patterns and frequencies with wet spell frequencies typically between 30 and $70 \%$ except for orographic regions (e.g., Cameroon mountains and Guinea highlands) which experience about 80 percent of wet days. This is consistent across all the observations. Considering the ensemble members, it is observed that the majority (e.g., MPI-ESM1-2-LR, MPI-ESM1-2-h, CanESM5, INM-CM5-0, IPSL-CM6A-LR, TaiESM1, MRI-ESM2-0, MIROC6, INM-CM4-8, SAM0-UNICON, NESM3, ACCESS-ESM1-5, MPI-ESM-1-2-HAM, and GFDL-ESM4) represent an overestimation of frequencies ranging between 80 and 100 percent. On the contrary to other models, FGOALS-f3-L shows similar frequency distribution to GPCP but does not record spells further north as seen in GPCP. In general, all ensemble members explicitly show the pattern of wet days but with high discrepancies in their frequencies. Despite the weak performance in the models' ability to capture some daily precipitation features
Table 6 Relative standard deviation (RSD) of observational datasets and CMIP6 datasets for SDII, frequency of heavy rainfall (freq of HR) and extreme precipitation at $95 \%$

\begin{tabular}{|c|c|c|c|}
\hline Models & SDII (\%) & $\begin{array}{l}\text { FREQ OF } \\
\text { HR }(\%)\end{array}$ & $\begin{array}{l}\text { Extremes at } \\
95 \%(\%)\end{array}$ \\
\hline GPCP & 28.6 & 38.3 & 60.8 \\
\hline CHIRPS & 21.4 & 41.7 & 63.8 \\
\hline TAMSAT & 19.9 & 34.8 & 62.9 \\
\hline MPI-ESM1-2-LR & 25.2 & 97.8 & 69.7 \\
\hline MPI-ESM1-2-HR & 23.2 & 82.7 & 44.8 \\
\hline CanESM5 & 227 & 32.5 & 37.3 \\
\hline BCC-ESM1 & 38.4 & 34.9 & 42.9 \\
\hline INM-CM5-0 & 17.2 & 24.3 & 22.0 \\
\hline KACE-1-0-G & 27.6 & 34.6 & 29.8 \\
\hline FGOALS-f3-L & 55.6 & 72.8 & 72.9 \\
\hline BCC-CSM2-MR & 51.5 & 33.7 & 45.7 \\
\hline IPSL-CMGA-LR & 27.1 & 49.2 & 60.0 \\
\hline TAiESM1 & 32.9 & 41.5 & 28.6 \\
\hline MRI-ESM2-0 & 33.7 & 39.5 & 39.5 \\
\hline NORESM2-MM & 36.2 & 37.6 & 40.6 \\
\hline MIROC6 & 30.2 & 29.4 & 34.8 \\
\hline ACCESS-CM2 & 31.2 & 56.2 & 45.6 \\
\hline INM-CM4-8 & 16.9 & 27.8 & 21.4 \\
\hline SAMO-UNICON & 36.51 & 34.7 & 27.8 \\
\hline NESM3 & 26.6 & 69.3 & 44.1 \\
\hline ACCESS-ESM1-5 & 35.7 & 45.3 & 40.6 \\
\hline FGOALS-g3 & 24.9 & 38.0 & 41.6 \\
\hline MPI-ESM-1-1-HAM & 24.7 & 59.6 & 31.6 \\
\hline GFDL-ESM4 & 45.8 & 43.3 & 46.0 \\
\hline
\end{tabular}

over West Africa, there seems to be a fair agreement among CMIP6 simulations and observation in rainfall frequency unlike in their intensities.

In Fig. 5, frequencies of mean heavy rainfall events are expressed as days within the monsoon seasonal days. From observation, all 3 observational datasets (GPCP, CHIRPS, and TAMSAT) record approximately the same frequencies of heavy rainfall events along the Guinea highlands with some disparities along the Cameroon mountains. CanESMS, MRI-ESM2-0, NESM3, and ACCESS-ESM1-5 shows some similarity to the pattern of the frequencies identified in the observational dataset but mostly with a different frequency of events. MPI-ESM1-2-h, INM-CM5-0, KACE-1-0-G, BCC-CSM2-MR, IPSL-CM6A-LR, INM-CM4-8, ACCESSCM2, and MPI-ESM-1-2-HAM present lower frequencies of mean heavy rainfall events. BCC-CSM2-MR, INM-CM4-8, and MPI-ESM1-2-h spatially show spatial intensities ranging between 3 and 13 days along the Guinea Coast-Savanna regions. These are underestimations when compared to observational datasets. In MIROC6, NESM3, BCC-ESM1, FGOALS-g3, and GFDL-ESM4 the frequencies over 
Sierra Leone and Guinea are overestimated as compared to observations at frequencies from 10 to 25 days. Majority of CMIP6 ensemble members capture the pattern with the highest frequencies along the Guinea-Sierra Leone stretch and the Cameroon highlands. The performance of the models to represent the frequency of heavy rainfall can be ranked based on the values of the RMSE. IPSL-CMGALR has the best representation of the frequency of heavy rainfall with $0.86 \mathrm{~mm} /$ day and $0.83 \mathrm{~mm} /$ day when compared with CHIRPS and TAMSAT, respectively. TaiESM1 also gives the best performance with $0.85 \mathrm{~mm} /$ day when compared with GPCP. It is interesting to note that MIROC6 and GFDL-ESM4 recorded the largest errors against all three observational datasets.

\subsection{Daily Extreme Precipitation Events (95th Percentile)}

The extreme precipitation events greater than the 95th percentile are presented in Fig. 6. The model simulations show wide variabilities among themselves as well as with GPCP. Relative to GPCP, CanESM5, BCC-ESM1, FGOALS-f3-L, MIROC6, GFDL-ESM4 simulate extreme precipitation events with higher estimates with spatial variations while MPI-ESM1-2-LR, MPI-ESM1-2-h, KACE-1-0-G, INMCM5-0, NESM3, ACCESS-CM2, TaoESM1, MRI-ESM2-0, NorESM2-MM, ACCESS-ESM1-5, FGOALS-g3, and MPIESM-1-2-HAM depict similar patterns. It is important to note that MIROC6, BCC-ESM1, CanESM5, and GFDLESM4 show greater than expected estimates than all observation datasets over the coast. There is a spatial disparity to some overestimation which cannot be generalized. For instance, TaiESM1, MRI-ESM2-0, FGOALS-g3, and IPSLCM6A-LR mostly overestimate rainfall extreme events over the Guinea highlands and along the Cameroon mountains. The southern parts of the region (Guinea Coast-Savanna) show high extreme events whereas areas north of the region (Sahel-Sahara) show lower values of rainfall extremes. This means the southern regions experience more extreme rainfall events as compared to the northern regions. INM-CM4-8 on the other hand tends to produce a lower 95 th percentile over the entire domain due to lower intensities and a lower number of heavy precipitation events as mentioned earlier. The performance of models using RMSE is presented in Table 5. MIROC6 and GFDL-ESM4 show the largest errors in representing rainfall extremes as observed in the frequency of heavy rainfall events when compared with all observation datasets. On the other hand, INM-CM4-8 and INM-CM5-0 seem to perform well in representing extreme events as seen in observational datasets. In the case of TAMSAT, ACCESS-CM2 does well in representing extreme events with a minimum error of $1.26 \mathrm{~mm} /$ day.
The intercomparison of the relative standard deviation (RSD) of observational datasets and CMIP6 datasets during the monsoon season is displayed in Table 6. INM-CM4-8 and INM-CM5-0 display less deviation from their long-term average rainfall characteristics, with FGOALS-f3-L recording the highest deviation in rainfall intensity and extreme precipitation at the 95th percentile, while MPI-ESM12-LR shows the highest deviation in the frequency of heavy rainfall.

\subsection{Mean Maximum Wet Spell Length}

Comparisons between CMIP6 simulations and observations are shown in Fig. 7 for mean maximum wet spell length. The main features of the mean wet spell length patterns are captured by the models but with errors in their amplitude and exact location. FGOALS-f3-L and BCC-ESM1 models out of the 21 models used in the study show results consistent with observations. The remaining models present a wetter climate than the observed with KACE-1-0-G and BCC-CSM2-MR showing a wetter climate only over Liberia, Sierra Leone, north of Nigeria, and Cameroon than the observed. Wetness to dominate in south-western Africa in all the other models. Some regions in the midlatitudes experience slight wetness but these features are robustly simulated by the models. Overall, the majority of models considered were inconsistent with observations.

\subsection{Mean Maximum Dry Spell Length}

The mean maximum dry spell length is calculated and presented spatially in Fig. 8. The models capture different magnitudes of the dry spell and high spatial variability. For instance, MPI-ESM1-2-LR, MPI-ESM1-2-h, FGOALSf3-L, ACCESS-CM2, MRI-ESM2-0, NESM3, ACCESSESM1-5, FGOALS-g3, MPI-ESM-1-2-HAM, and GFDALESM4 show a higher number of spell length ranging between 70 and 100 days, which opposes what the observations presented. In addition, the aforementioned models show a wider area of dry spell lengths relative to the observations. From observational datasets, the high spell lengths are seen around northern Niger but are not represented by the models. Most of the models show a higher number of spells around $15^{\circ}$ $\mathrm{N}$. In addition, the dry spell length that is observed around the Cameroonian highlands is not captured in any of the CMIP6 simulations.

\section{Summary and Conclusions}

The ability of GCMs to simulate robust precipitation change at the daily timescale is of importance to society and likewise for decision and policymakers in managing water 

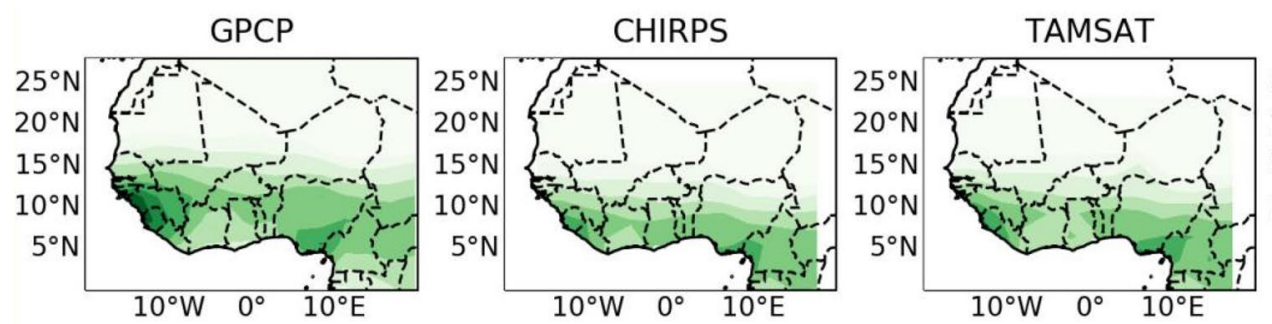

MPI-ESM1-2-LR
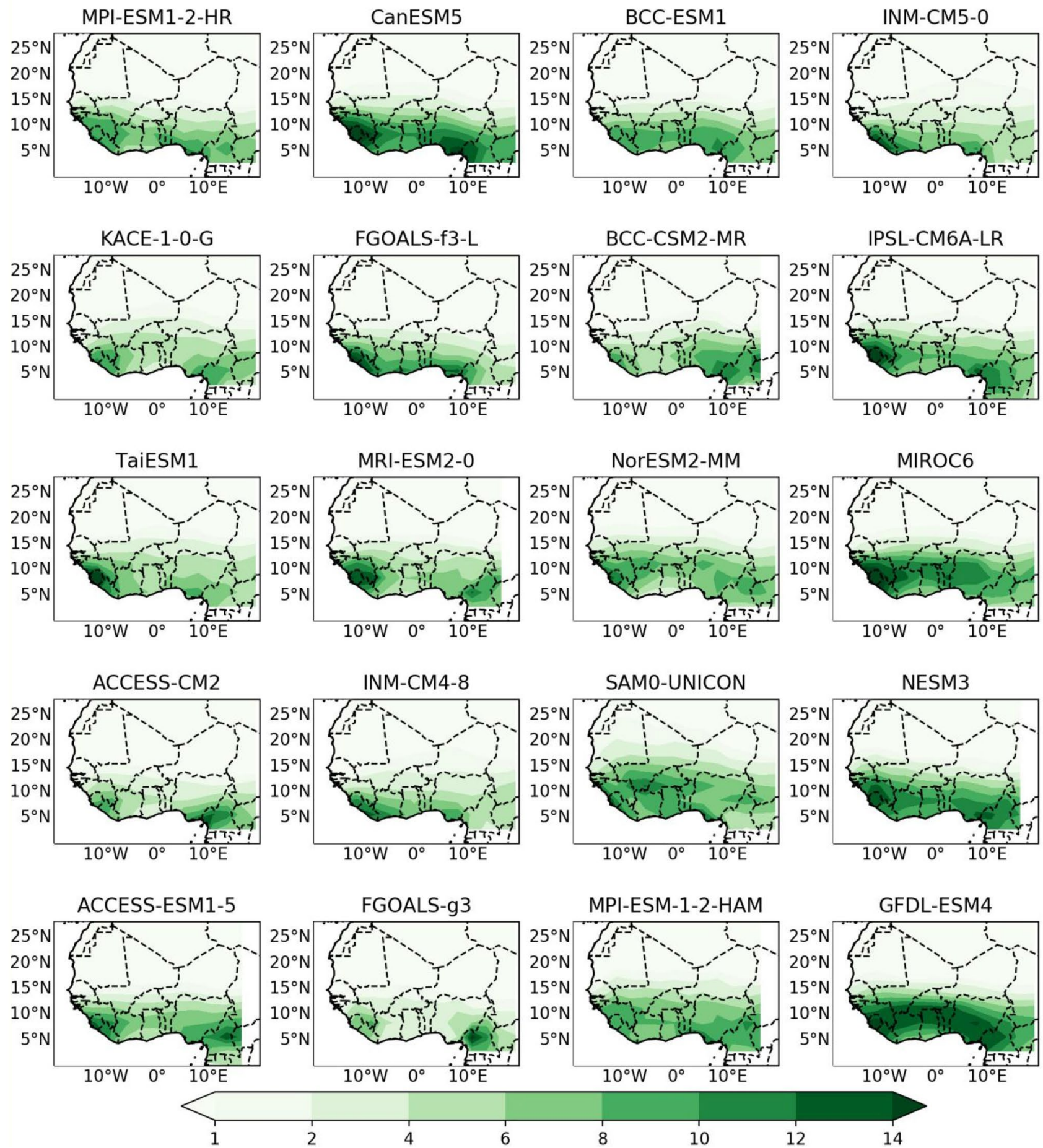

Fig. 2 Mean JJAS rainfall climatology (mm/day) from GPCP, CHIRPS and TAMSAT observational dataset and each of the CMIP6 over West Africa for the period 1997-2014 

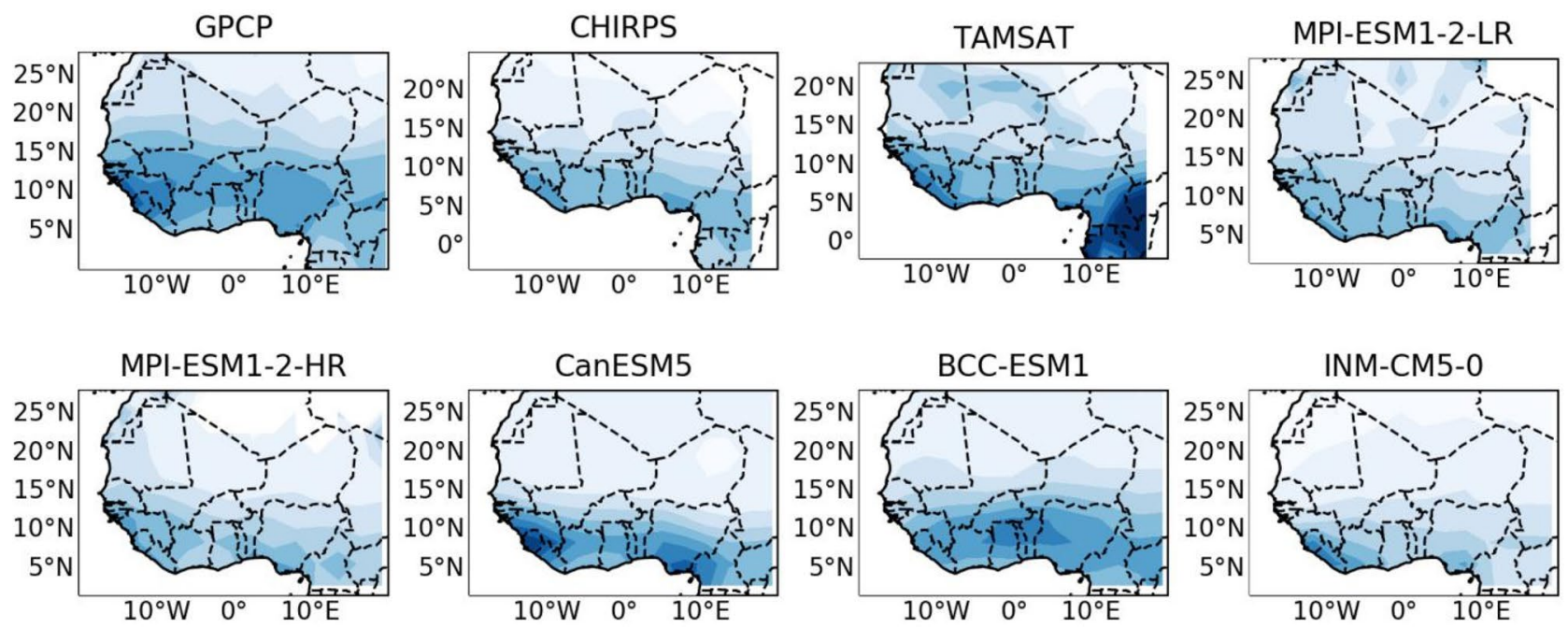

KACE-1-0-G

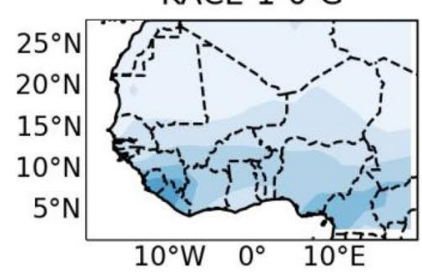

TaiESM1

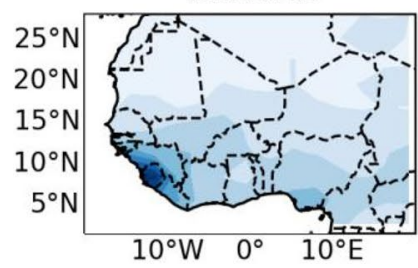

ACCESS-CM2

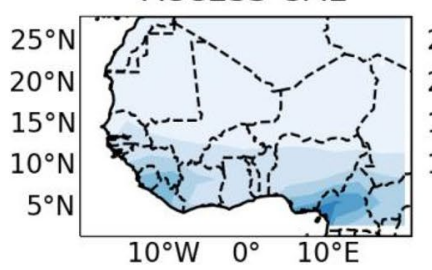

ACCESS-ESM1-5

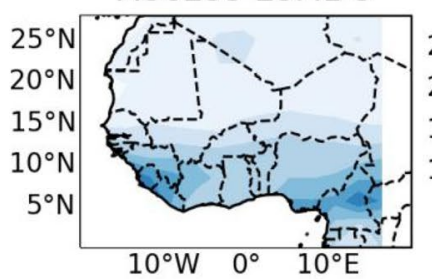

FGOALS-f3-L

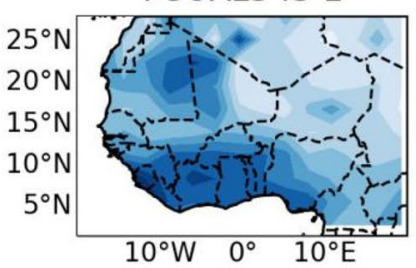

MRI-ESM2-0

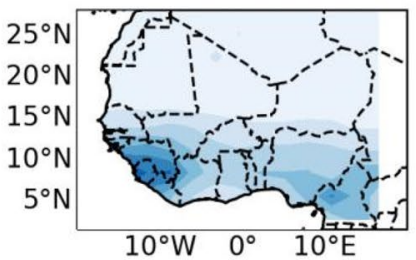

INM-CM4-8

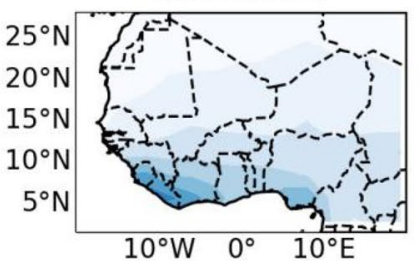

BCC-CSM2-MR

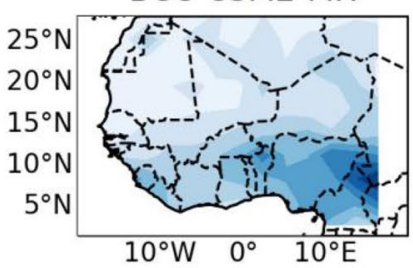

NorESM2-MM

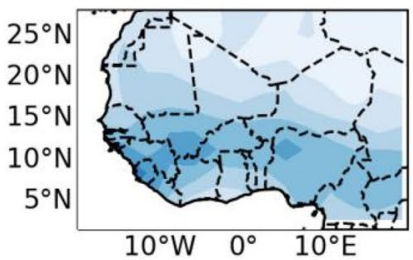

SAMO-UNICON

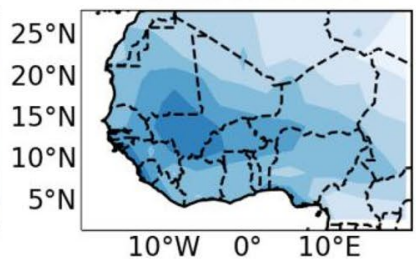

IPSL-CM6A-LR

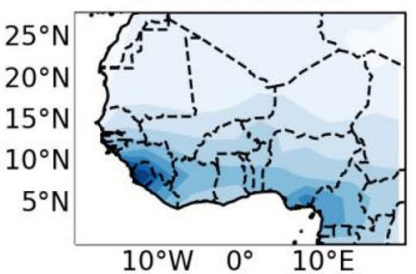



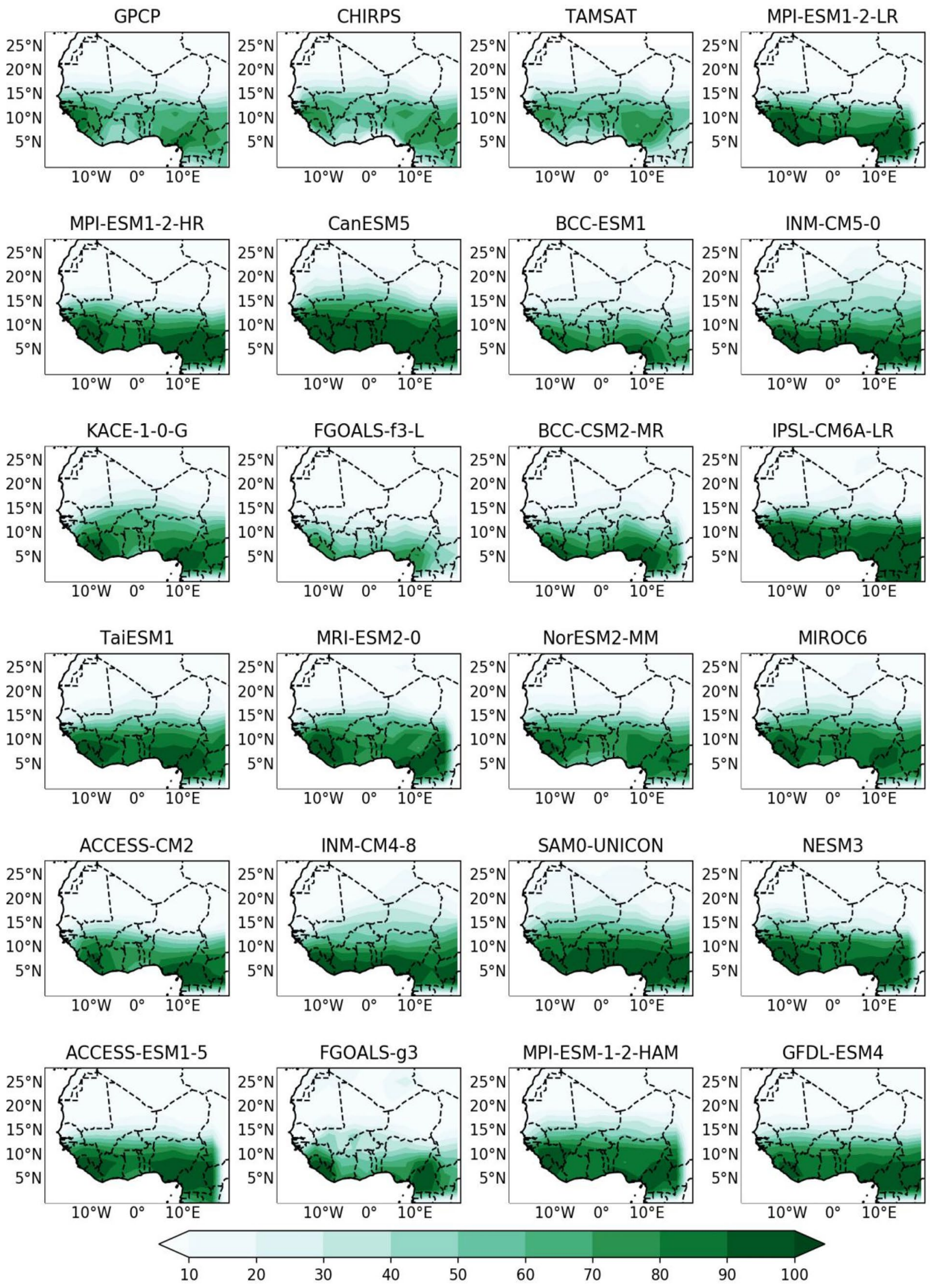

Fig. 4 Same as Fig. 3 but for mean frequency of wet days (expressed in percent of total seasonal days) 

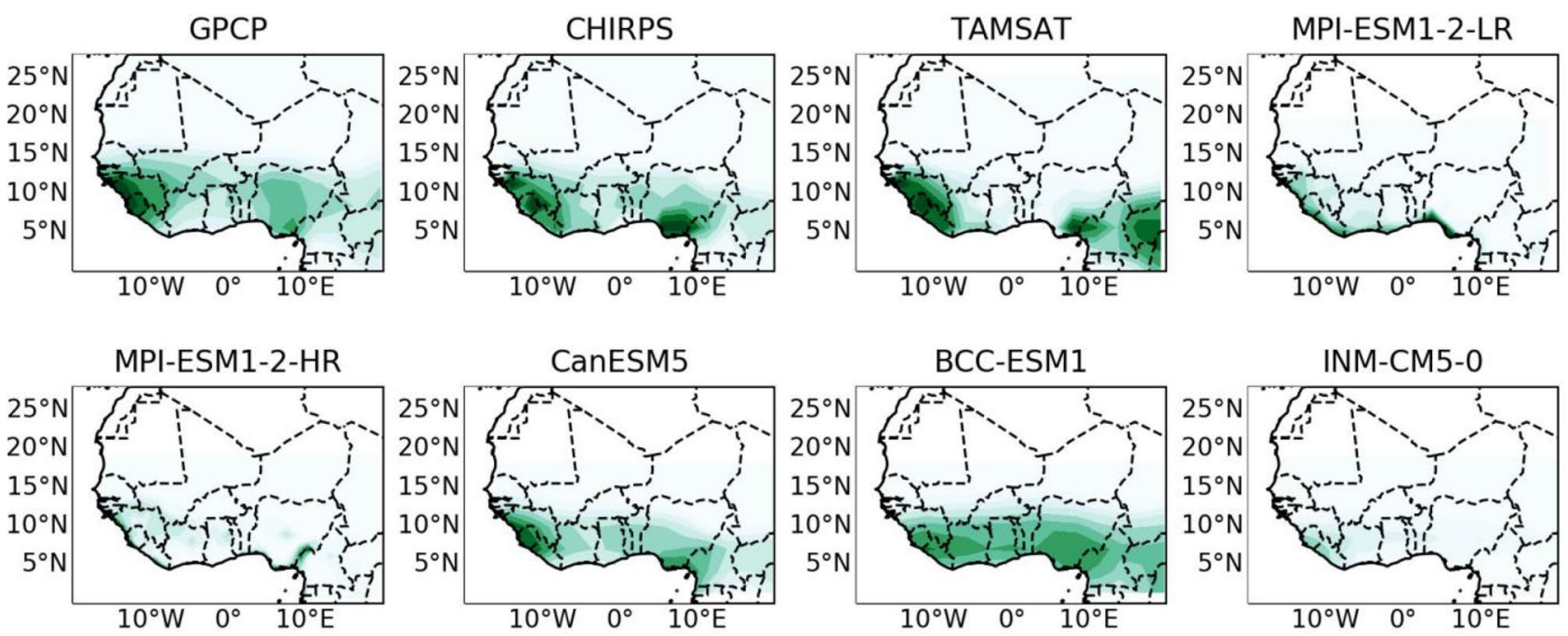

KACE-1-0-G

FGOALS-f3-L
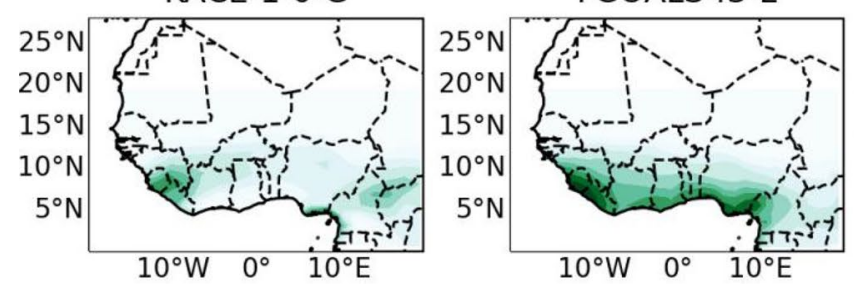

BCC-CSM2-MR

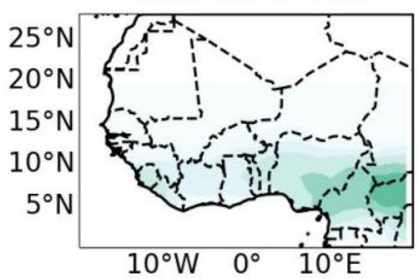

IPSL-CM6A-LR
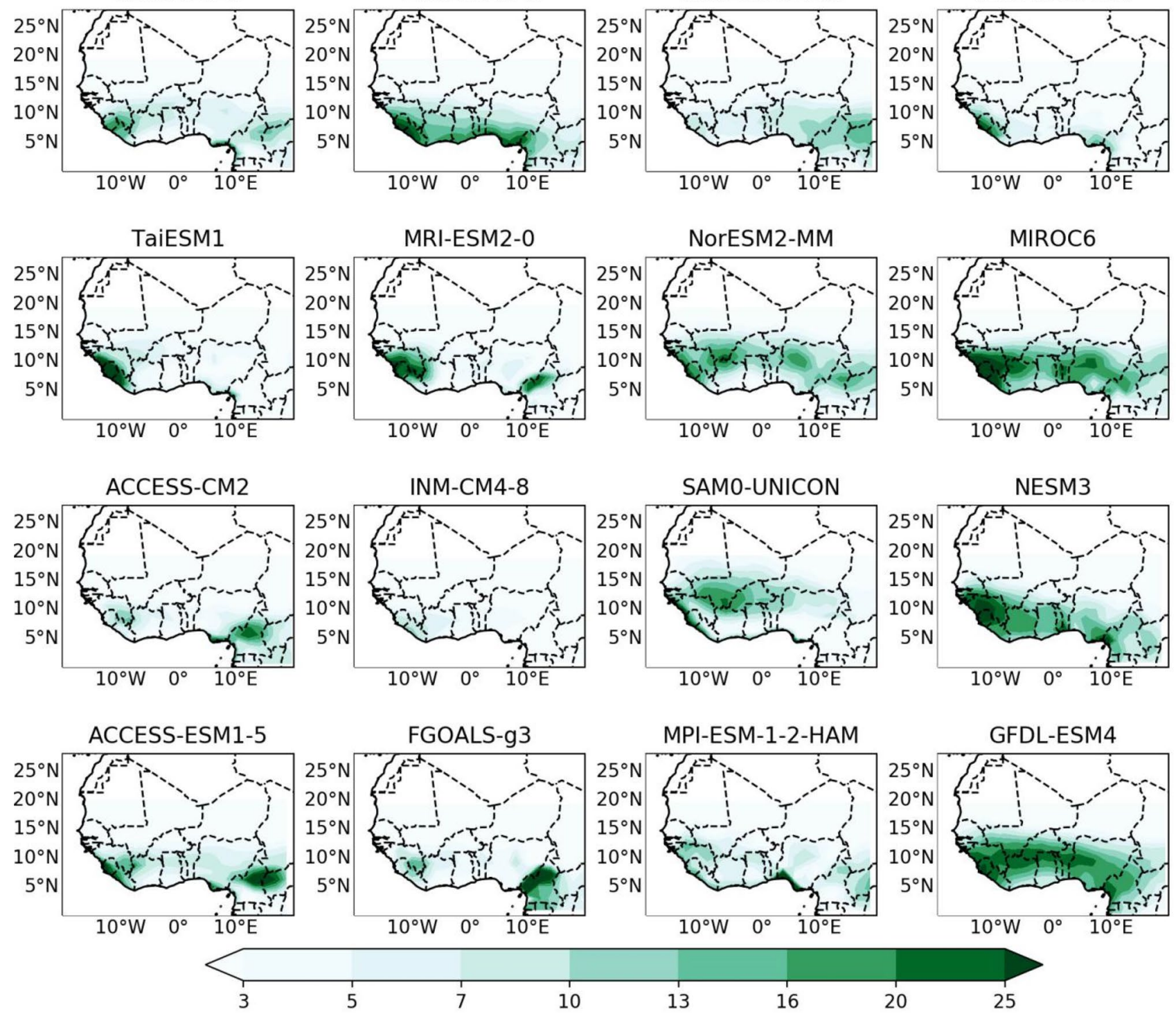

13

20

25

Fig. 5 Same as Fig. 3 but for mean frequency of heavy rainfall events (expressed in days within the season) 

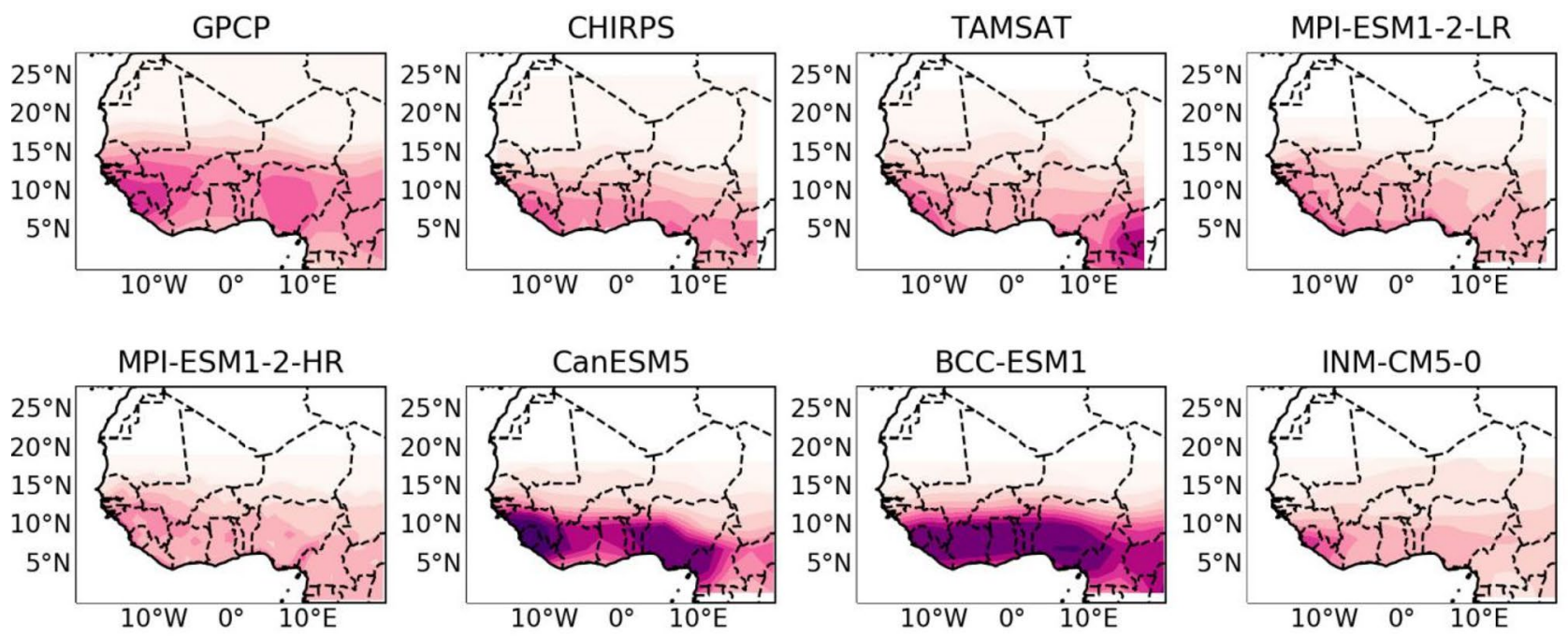

KACE-1-0-G

FGOALS-f3-L

BCC-CSM2-MR
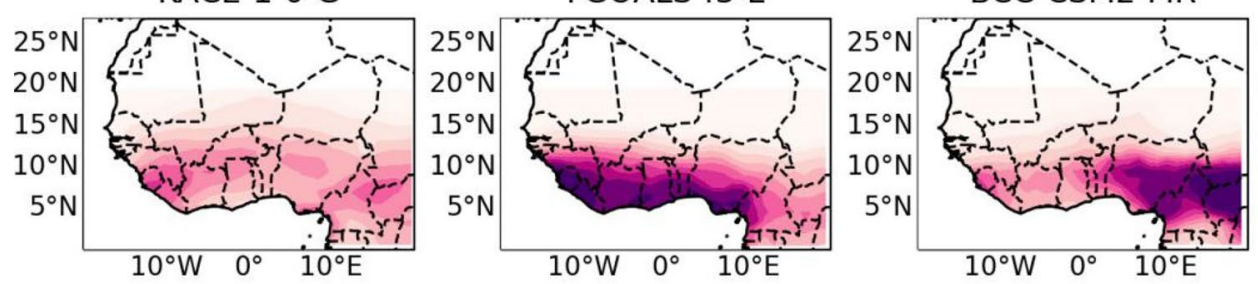

IPSL-CM6A-LR
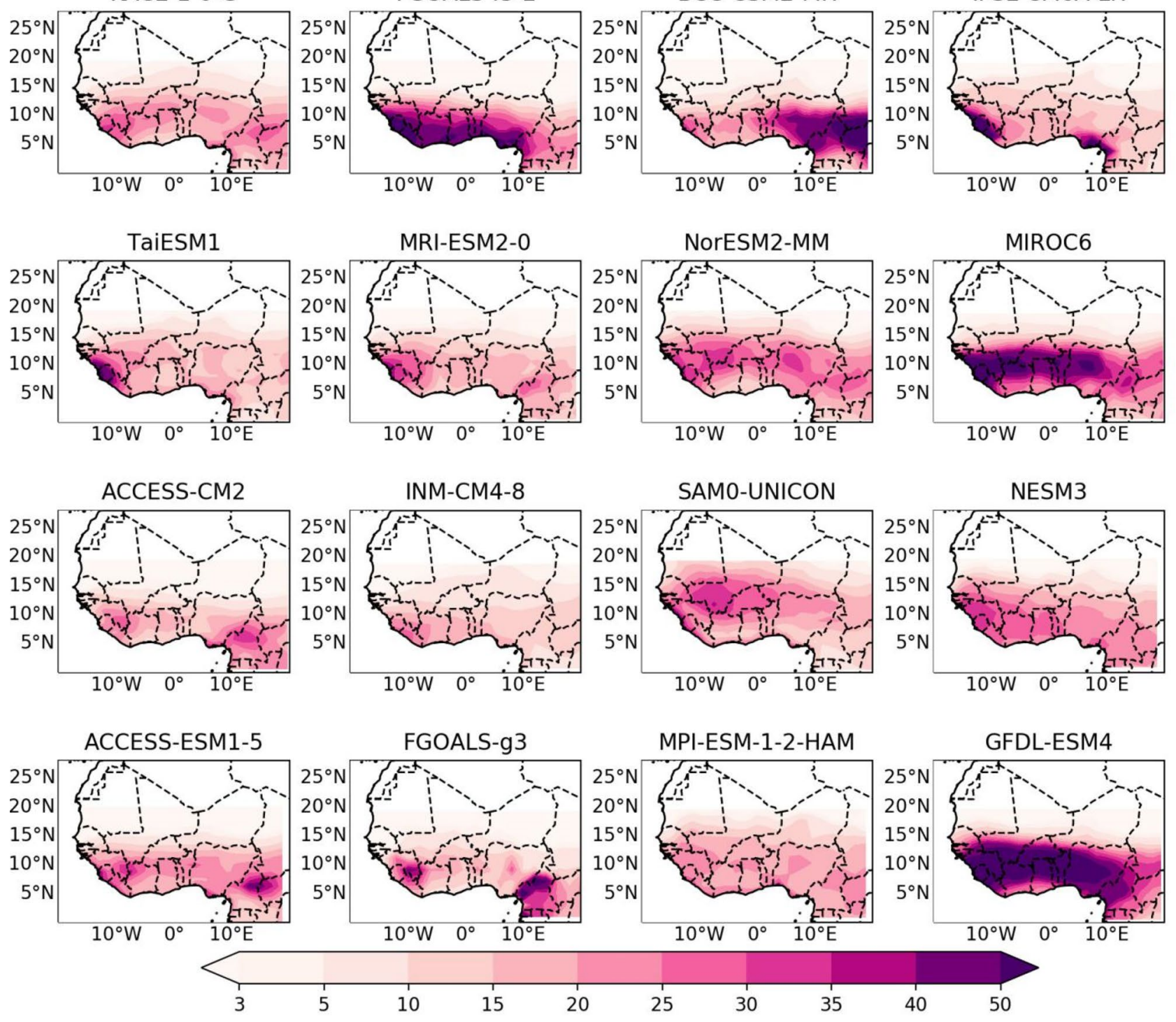

Fig. 6 Same as Fig. 3 but for mean 95th percentile of daily rainfall events (mm/day) 

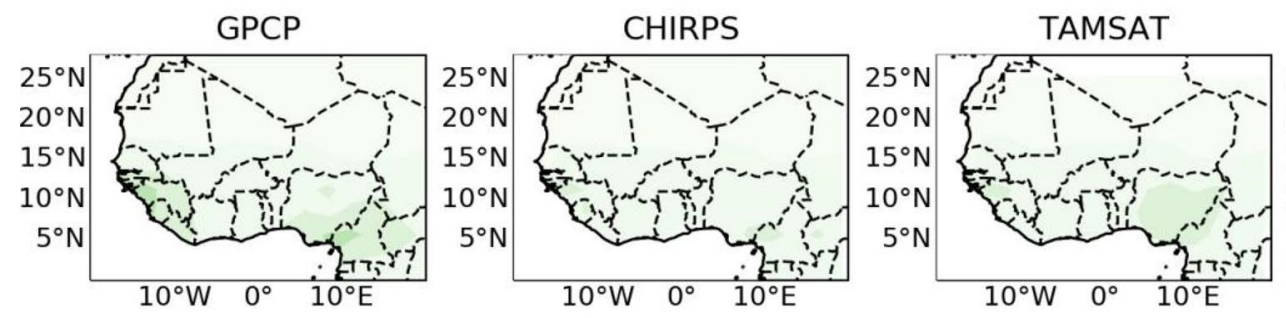

MPI-ESM1-2-LR

MPI-ESM1-2-HR
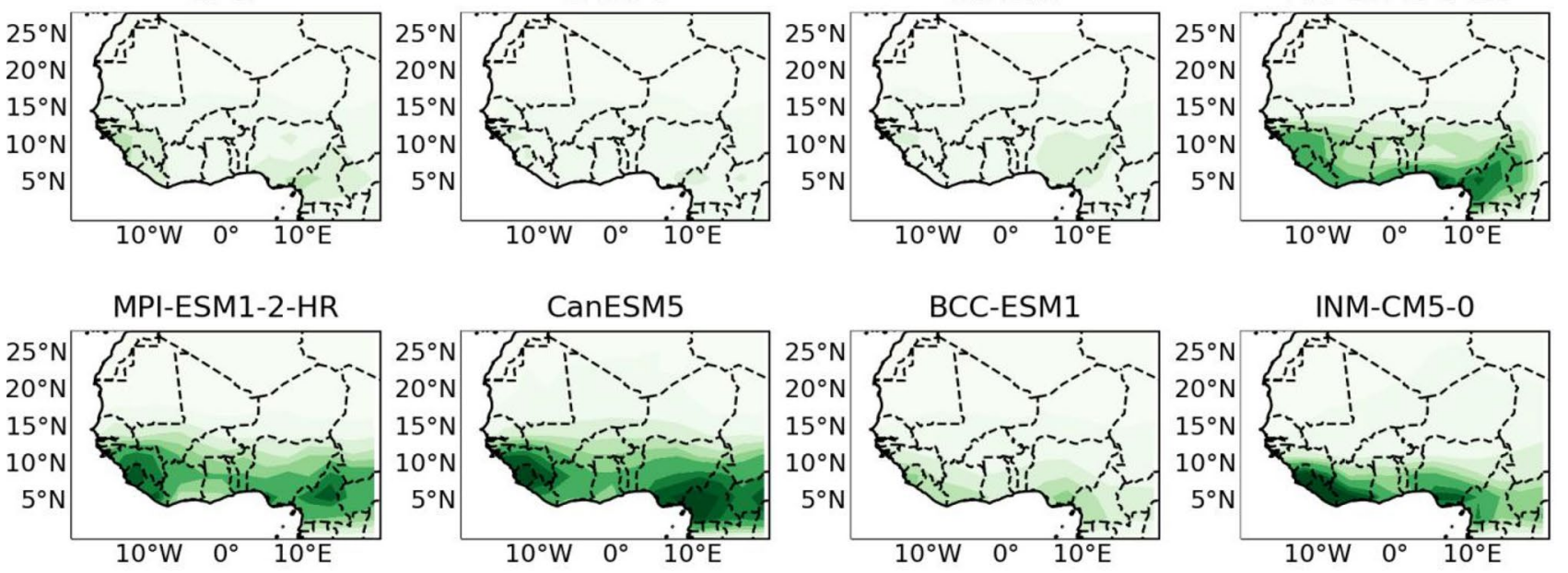

FGOALS-f3-L

BCC-CSM2-MR
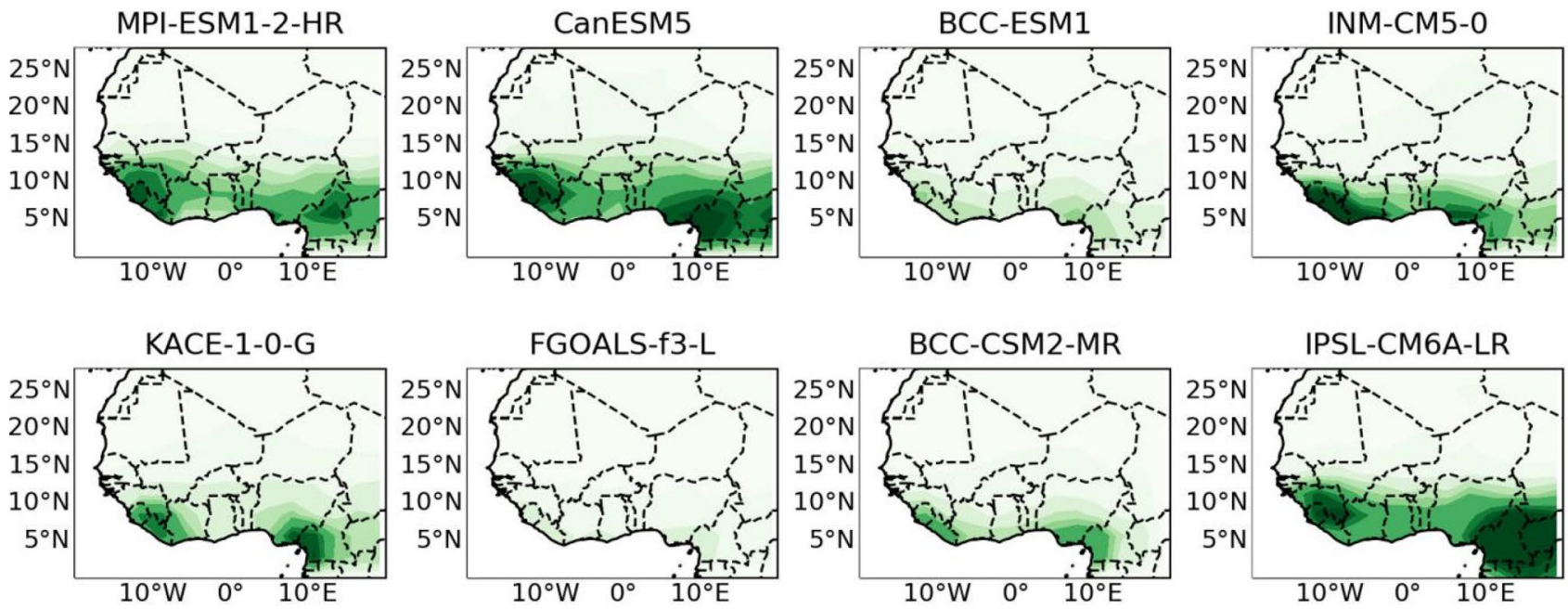

TaiESM1
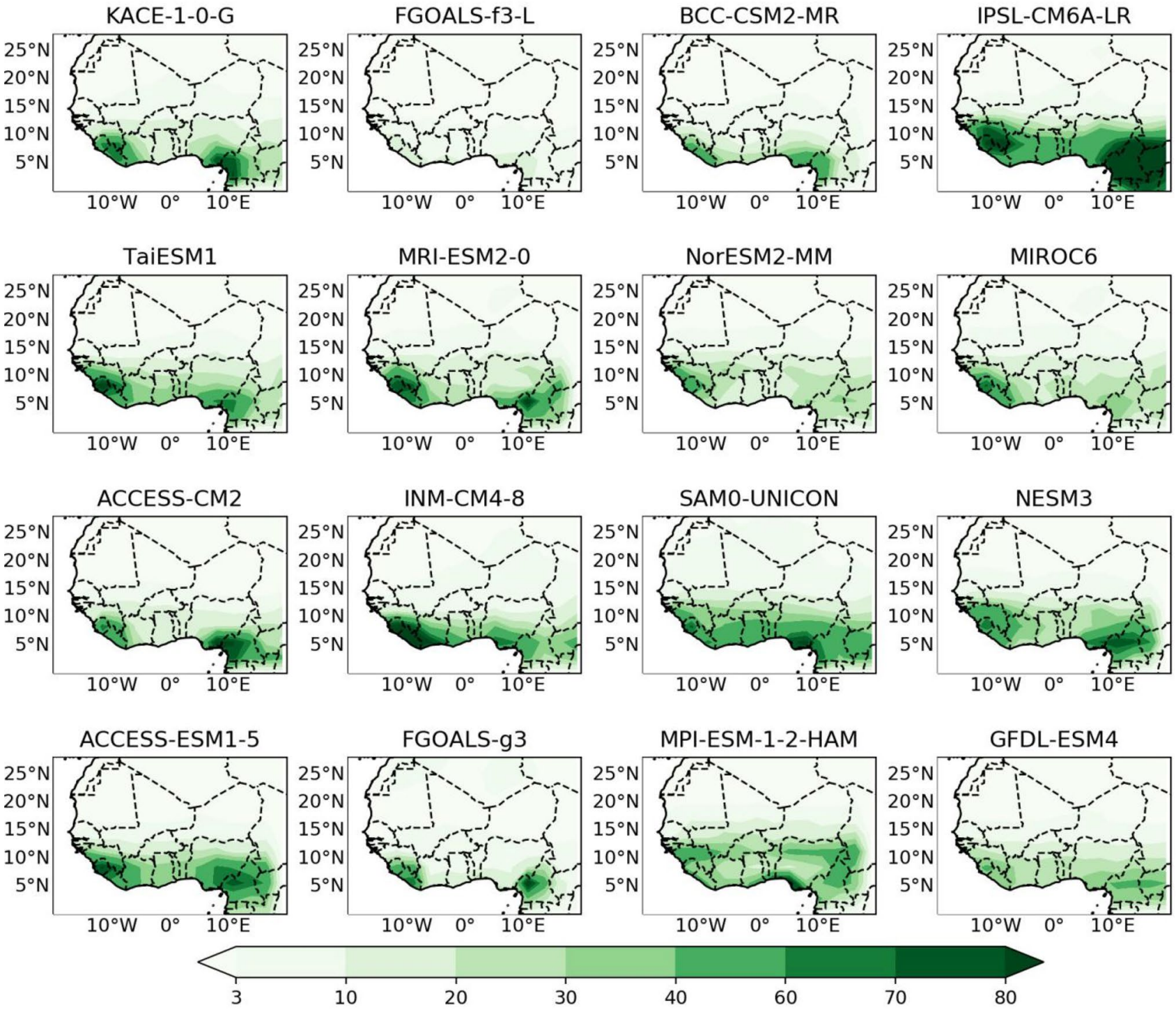

70

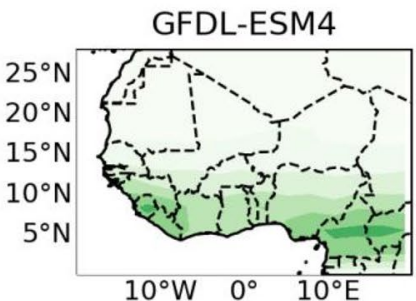

Fig. 7 Same as Fig. 3 but for mean maximum wet spell length (expressed in percent of total seasonal days) 

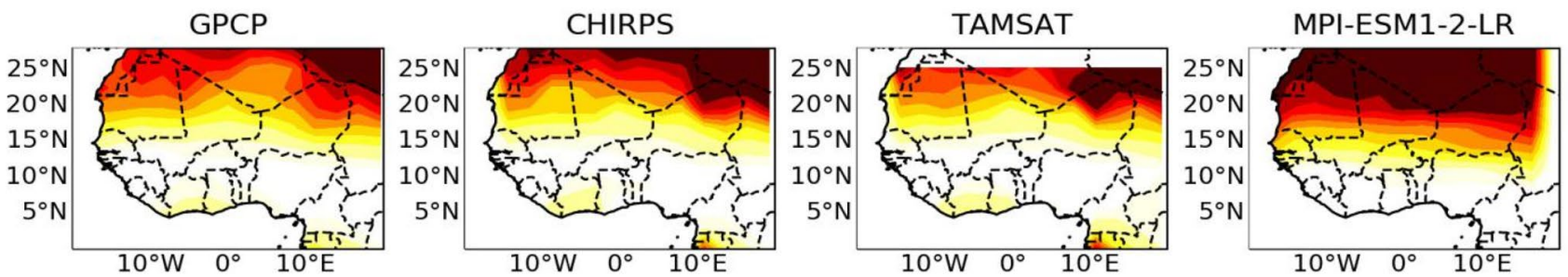

MPI-ESM1-2-HR

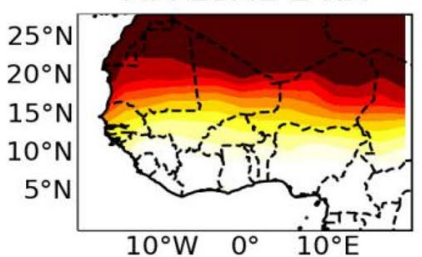

CanESM5

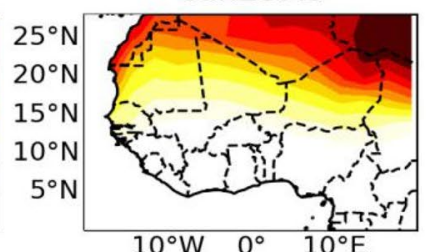

BCC-ESM1

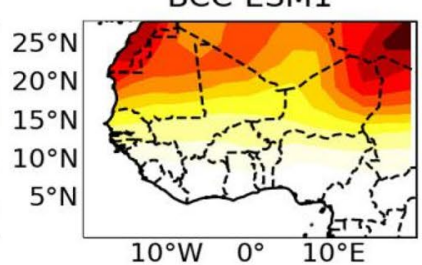

INM-CM5-0
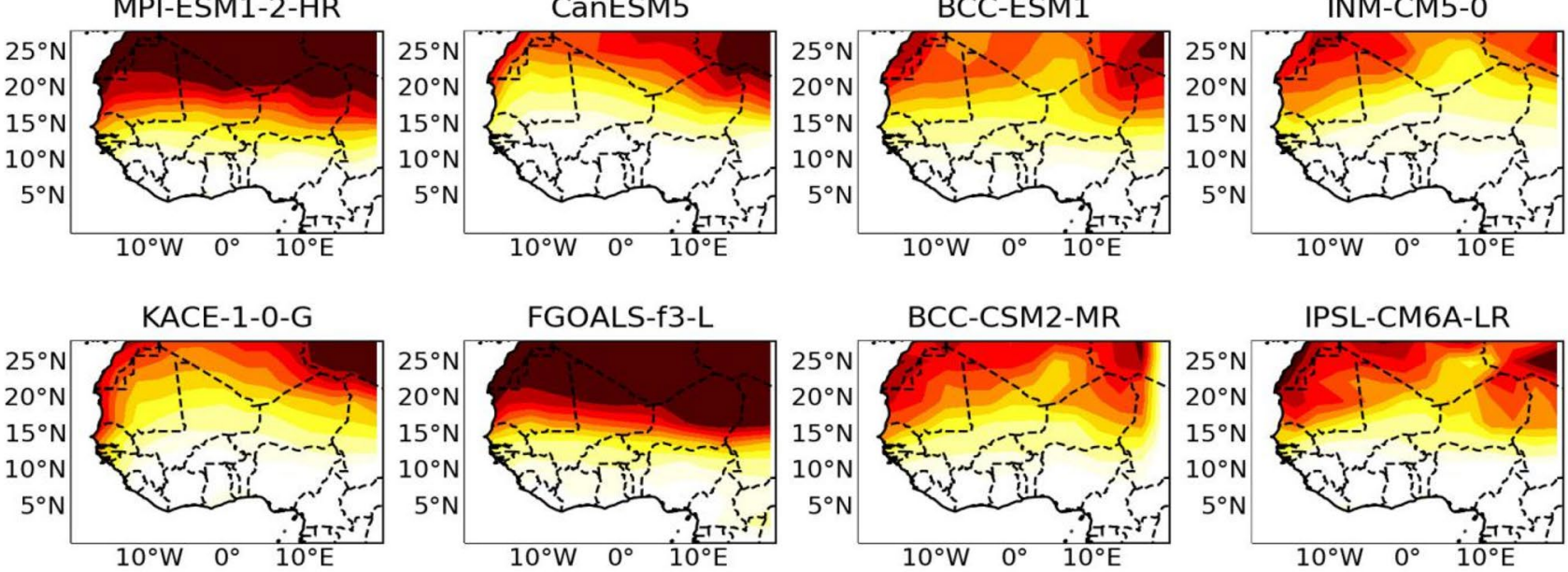

TaiESM1
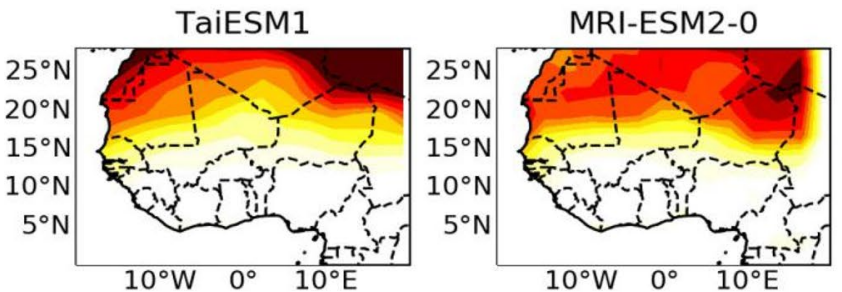

NorESM2-MM
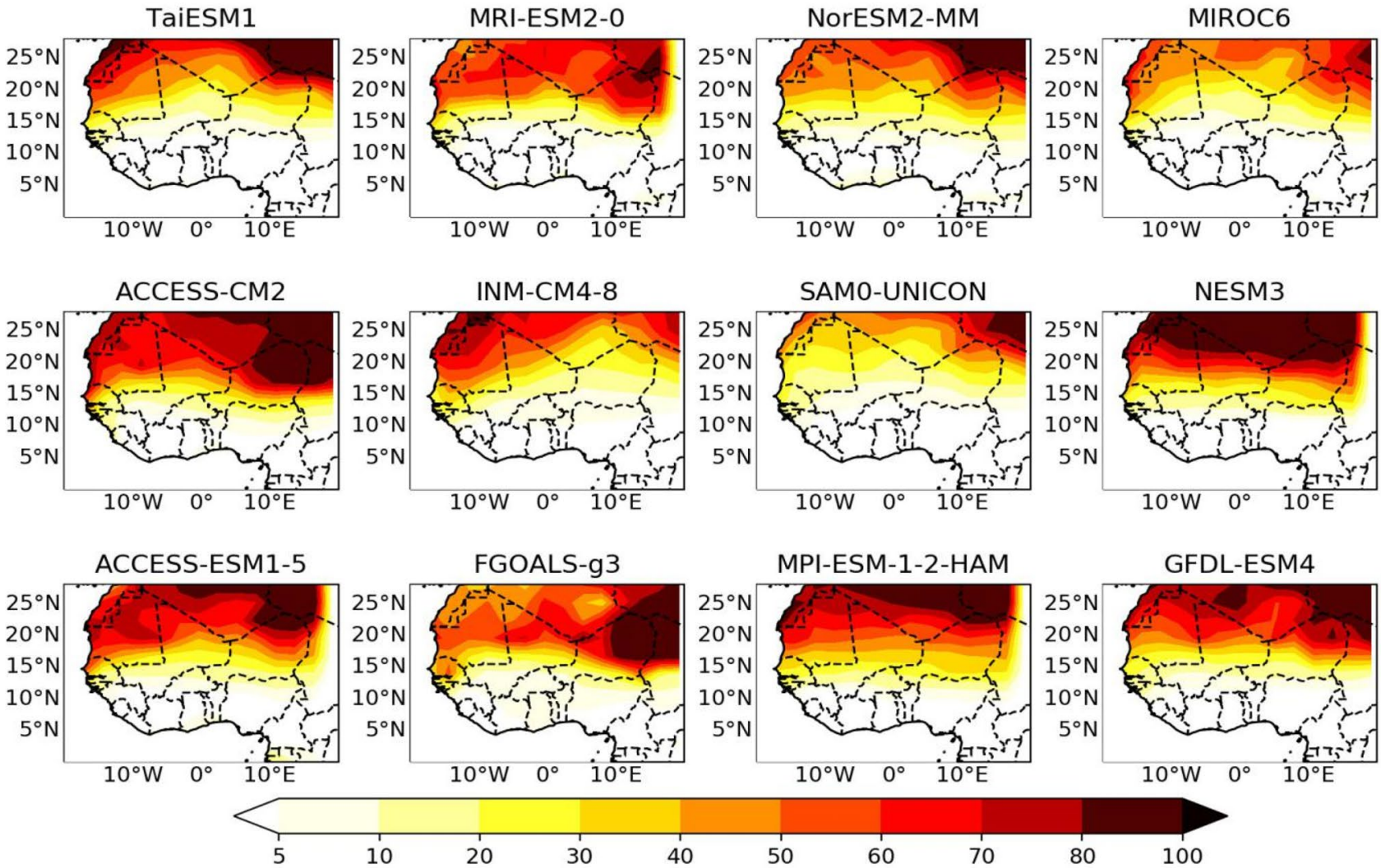

Fig. 8 Same as in Fig. 3 but for mean maximum dry spell length (expressed in percent of total seasonal days) 
resources, drought, and flood monitoring and agriculture. However, identifying and quantifying daily precipitation events as a proxy to understand and assess climate change over Africa is a difficult task. Thus, it is important to assess the performance of the new state-of-the-art CMIP6 models in representing daily precipitation characteristics over West Africa.

In this study, we present an evaluation and intercomparison of the daily precipitation characteristics and extremes of 21 GCMs from the CMIP6 model stack. Three observational datasets (GPCP, CHIRPS, and TAMSAT) were used for the validation of the model simulations. The results show that observed datasets present nearly the same spatial pattern and magnitude of rainfall characteristics, but models show substantial discrepancies in comparison. The focus is on the daily rainfall characteristics such as mean rainfall climatology, and extreme indices such as the intensity of rainy days, frequency of heavy rainfall, and extreme events as well as mean maximum length of dry and wet spells within the monsoon season JJAS over West Africa from 1997 through 2014. The models were further subjected to statistical assessments to quantify their performance relative to the observations. We used the root mean squared error (RMSE) and relative standard deviation (RSD) to quantify the performance of the models. The RMSE gives the errors and RSD gives the standard deviation of a set of data as small or large when compared to the mean.

The observation datasets regardless of their differences agree in most of the statistics and spatial representations. For precipitation intensity, the observations present a similar pattern and magnitude. Similarly, the simulations demonstrate a general pattern of the monsoon season in comparison with the observations. However, considerable discrepancies exist among the simulations and relative to the observations. For example, substantial differences exist in terms of mean precipitation climatology, the intensity of rainy days, frequency, extremes, and duration of rainfall events during the WAM period. FGOALS-f3-L and GFDL-ESM4 present a more intensified daily rainfall event. The models clearly depict the frequency of wet days similar to observations but present much more intensity in the Guinea Highlands and Cameroon mountains, resulting from the simulation of a larger number of heavy precipitation events indicating more intense extremes. Specifically, more intense extremes are expressed in the 95th percentiles in CanESM5, BCC-ESM1, FGOALf3-L, BCC-CSM2-MR, MIROC6, and GFDL-ESM4. All the models overestimate the mean maximum wet spell length except FGOALS-f3-L which presents a similar magnitude as that of the observations. The spatial patterns of the mean maximum dry spell length expressed as a percent of total seasonal days from the observational dataset and the models show a good general agreement across the different models, and the observations except for NESM3, FGOALS-f3-L, MPI-ESM1-2-h, and MPI-ESM1-2-LR that overestimate the dry spell length in the Sahara subregion. The computed RMSE values show the weakness in MIROC6 and GFDLESM4 in representing the correct extreme indices such as frequency of heavy rainfall and 95 th percentile extremes. For the frequency of heavy rainfall, TaiESM1 performs better when compared with GPCP and IPSL-CMGA-LR performs better when compared with CHIRPS and TAMSAT. This observation is different in the case of the 95th percentile extreme where INM-CM5-0 and INM-CM4-8 models perform more closely to all observational datasets compared to the rest of the models.

The investigation of the model performance of the individual models from CMIP6 suggested that the skill of the models generally varies from model to model at spatial scales. The difficulty in attributing discrepancies in individual model datasets may be due to the systematic differences in the representation of hydrological processes since the process is vital in precipitation formation. It can be inferred from the present study that no single model exhibits all features of the observational datasets. The discrepancies in the simulations give room for improvement of the models in the next version of CMIP. The results offer useful information about the precipitation in CMIP6 over West Africa and can serve as a reference for the new generation of climate models over the continent.

Acknowledgements The authors thank the World Climate Research Program for making the CMIP6 dataset available through the Earth System Grid Federation (ESGF) archiving and free access for this research. The second author is grateful to the University of Cape Town for research assistance. This research is under the MS4CR Project (Climate Change Science Project) supported by the African Institute for Mathematical Sciences, www.nexteinstein.org, with financial support from the Government of Canada, provided through Global Affairs Canada, www.international.gc.ca, and the International Development Research Centre, www.idrc.ca.

\section{Compliance with Ethical Standards}

Conflict of Interest The authors declare no potential conflict of interests.

Open Access This article is licensed under a Creative Commons Attribution 4.0 International License, which permits use, sharing, adaptation, distribution and reproduction in any medium or format, as long as you give appropriate credit to the original author(s) and the source, provide a link to the Creative Commons licence, and indicate if changes were made. The images or other third party material in this article are included in the article's Creative Commons licence, unless indicated otherwise in a credit line to the material. If material is not included in the article's Creative Commons licence and your intended use is not permitted by statutory regulation or exceeds the permitted use, you will need to obtain permission directly from the copyright holder. To view a copy of this licence, visit http://creativecommons.org/licenses/by/4.0/. 


\section{References}

Abiodun BJ, Abba Omar S, Lennard C, Jack C (2016) Using regional climate models to simulate extreme rainfall events in the Western Cape, South Africa. Int J Climatol. https://doi.org/10.1002/ joc. 4376

Ajibola FO, Zhou B, Gnitou GT, Onyejuruwa A (2020) Evaluation of the performance of CMIP6 HighResMIP on West African precipitation. Atmosphere. https://doi.org/10.3390/atmos11101053

Akinsanola AA, Zhou W (2019a) Projection of West African summer monsoon rainfall in dynamically downscaled CMIP5 models. Clim Dyn. https://doi.org/10.1007/s00382-018-4568-6

Akinsanola AA, Zhou W (2019b) Projections of West African summer monsoon rainfall extremes from two CORDEX models. Clim Dyn. https://doi.org/10.1007/s00382-018-4238-8

Akinsanola AA, Ogunjobi KO, Gbode IE, Ajayi VO (2015) Assessing the capabilities of three regional climate models over CORDEX Africa in simulating west African summer monsoon precipitation. Adv Meteorol. https://doi.org/10.1155/2015/935431

Akinsanola AA, Kooperman GJ, Reed KA, Pendergrass AG, Hannah WM (2020) Projected changes in seasonal precipitation extremes over the US in CMIP6 simulations. Environ Res Lett. https://doi.org/10.1088/1748-9326/abb397

Almazroui M (2020) Changes in temperature trends and extremes over Saudi Arabia for the period 1978-2019. Adv Meteorol. https://doi.org/10.1155/2020/8828421

Almazroui M (2020a) Rainfall trends and extremes in Saudi Arabia in recent decades. Atmosphere 11:964. https://doi.org/10.3390/ atmos11090964

Almazroui M, Islam MN (2019) Coupled model inter-comparison project database to calculate drought indices for Saudi Arabia: a preliminary assessment. Earth Syst Environ 3:419-428. https ://doi.org/10.1007/s41748-019-00126-9

Almazroui M, Saeed F, Saeed S, Nazrul Islam M, Ismail M, Klutse NAB, Siddiqui MH (2020) Projected change in temperature and precipitation over Africa from CMIP6. Earth Syst Environ 4:455-475. https://doi.org/10.1007/s41748-020-00161-x

Barlow M, Gutowski WJ, Gyakum JR, Katz RW, Lim YK, Schumacher RS, Wehner MF, Agel L, Bosilovich M, Collow A, Gershunov A, Grotjahn R, Leung R, Milrad S, Min SK (2019) North American extreme precipitation events and related largescale meteorological patterns: a review of statistical methods, dynamics, modeling, and trends. Clim Dyn. https://doi. org/10.1007/s00382-019-04958-z

Baumberger C, Knutti R, Hirsch Hadorn G (2017) Building confidence in climate model projections: an analysis of inferences from fit. Wiley interdisciplinary reviews. Clim Change. https:// doi.org/10.1002/wcc.454

Berg P, Moseley C, Haerter JO (2013) Strong increase in convective precipitation in response to higher temperatures. Nat Geosci. https://doi.org/10.1038/ngeo1731

Bi D, Dix M, Marsland S, Hirst T, O'Farrell1 S, Uotila P, Sullivan A, Yan H, Kowalczyk E, Rashid H, Franklin C, Watterson I, Sun Z, Zhou X, Puri K (2012) ACCESS: the Australian coupled climate model for IPCC AR5 and CMIP5. In: AMOS 18th Annual Conference : Connections in the Climate System: General Information, Programme and Abstracts Handbook : University of New South Wales, 31 Jan to 3 Feb 2012.

Boucher O, Servonnat J, Albright AL, Aumont O, Balkanski Y, Bastrikov V, Bekki S, Bonnet R, Bony S, Bopp L, Braconnot P, Brockmann P, Cadule P, Caubel A, Cheruy F, Codron F, Cozic A, Cugnet D, D'Andrea F, Vuichard N (2020) Presentation and evaluation of the IPSL-CM6A-LR climate model. J Adv Model Earth Syst. https://doi.org/10.1029/2019MS002010
Byun Y-H, Lim Y-J, Sung HM, Kim J, Sun M, Kim B-H (2019) NIMS-KMA KACE1.0-G model output prepared for CMIP6 CMIP amip. https://doi.org/10.22033/ESGF/CMIP6.8350

Cao J, Wang B, Yang YM, Ma L, Li J, Sun B, Bao Y, He J, Zhou X, Wu L (2018) The NUIST earth system model (NESM) version 3: description and preliminary evaluation. Geosci Model Dev. https://doi.org/10.5194/gmd-11-2975-2018

Crétat J, Vizy EK, Cook KH (2014) How well are daily intense rainfall events captured by current climate models over Africa? Clim Dyn. https://doi.org/10.1007/s00382-013-1796-7

Diallo I, Sylla MB, Camara M, Gaye AT (2013) Interannual variability of rainfall over the Sahel based on multiple regional climate models simulations. Theoret Appl Climatol. https://doi.org/10.1007/ s00704-012-0791-y

Eyring V, Bony S, Meehl GA, Senior CA, Stevens B, Stouffer RJ, Taylor KE (2016) Overview of the coupled model intercomparison project phase 6 (CMIP6) experimental design and organization. Geosci Model Dev. https://doi.org/10.5194/gmd-9-1937-2016

Funk C, Verdin A, Michaelsen J, Peterson P, Pedreros D, Husak G (2015) A global satellite-assisted precipitation climatology. Earth Syst Sci Data. https://doi.org/10.5194/essd-7-275-2015

Gaetani M, Flamant C, Bastin S, Janicot S, Lavaysse C, Hourdin F, Braconnot P, Bony S (2017) West African monsoon dynamics and precipitation: the competition between global SST warming and $\mathrm{CO}_{2}$ increase in CMIP5 idealized simulations. Clim Dyn. https:// doi.org/10.1007/s00382-016-3146-Z

Gutjahr O, Putrasahan D, Lohmann K, Jungclaus JH, Von Storch JS, Brüggemann N, Haak H, Stössel A (2019) Max planck institute earth system model (MPI-ESM1.2) for the high-resolution model intercomparison project (HighResMIP). Geosci Model Dev. https ://doi.org/10.5194/gmd-12-3241-2019

He B, Bao Q, Wang X, Zhou L, Wu X, Liu Y, Wu G, Chen K, He S, Hu W, Li J, Li J, Nian G, Wang L, Yang J, Zhang M, Zhang X (2019) CAS FGOALS-f3-L model datasets for CMIP6 historical atmospheric model intercomparison project simulation. Adv Atmos Sci. https://doi.org/10.1007/s00376-019-9027-8

Held IM, Guo H, Adcroft A, Dunne JP, Horowitz LW, Krasting J, Shevliakova E, Winton M, Zhao M, Bushuk M, Wittenberg AT, Wyman B, Xiang B, Zhang R, Anderson W, Balaji V, Donner L, Dunne K, Durachta J, Zadeh N (2019) Structure and Performance of GFDL's CM4.0 Climate Model. J Adv Modeli Earth Syst. https ://doi.org/10.1029/2019MS001829

Huffman G, Bolvin D (2013) GPCP version 2.2 SG combined precipitation data set documentation. NASA GSFC Doc.

Ibrahim B, Polcher J, Karambiri H, Rockel B (2012) Characterization of the rainy season in Burkina Faso and it's representation by regional climate models. Clim Dyn. https://doi.org/10.1007/ s00382-011-1276-x

James R, Washington R, Jones R (2015) Process-based assessment of an ensemble of climate projections for West Africa. J Geophys Res. https://doi.org/10.1002/2014JD022513

James R, Washington R, Abiodun B, Kay G, Mutemi J, Pokam W, Hart N, Artan G, Senior C (2018) Evaluating climate models with an African lens. Bull Am Meteor Soc. https://doi.org/10.1175/ BAMS-D-16-0090.1

Klutse NAB, Sylla MB, Diallo I, Sarr A, Dosio A, Diedhiou A, Kamga A, Lamptey B, Ali A, Gbobaniyi EO, Owusu K, Lennard C, Hewitson B, Nikulin G, Panitz HJ, Büchner M (2016) Daily characteristics of West African summer monsoon precipitation in CORDEX simulations. Theor Appl Climatol. https://doi. org/10.1007/s00704-014-1352-3

Klutse NAB, Abiodun BJ, Hewitson BC, Gutowski WJ, Tadross MA (2016) Evaluation of two GCMs in simulating rainfall inter-annual variability over Southern Africa. Theor Appl Climatol. https://doi. org/10.1007/s00704-014-1356-Z 
Law RM, Ziehn T, Matear RJ, Lenton A, Chamberlain MA, Stevens LE, Wang YP, Srbinovsky J, Bi D, Yan H, Vohralik PF (2017) The carbon cycle in the Australian community climate and earth system simulator (ACCESS-ESM1)—Part 1: model description and pre-industrial simulation. Geosci Model Dev. https://doi. org/10.5194/gmd-10-2567-2017

Maidment R, Black E, Young M (2017) TAMSAT Daily Rainfall Estimates (Version 3.0).

Mauritsen T, Bader J, Becker T, Behrens J, Bittner M, Brokopf R, Brovkin V, Claussen M, Crueger T, Esch M, Fast I, Fiedler S, Fläschner D, Gayler V, Giorgetta M, Goll DS, Haak H, Hagemann S, Hedemann C, Roeckner E (2019) Developments in the MPI-M earth system model version 1.2 (MPI-ESM1.2) and its response to increasing $\mathrm{CO}_{2}$. J Adv Model Earth Syst. https://doi. org/10.1029/2018MS001400

Nguyen P, Thorstensen A, Sorooshian S, Zhu Q, Tran H, Ashouri H, Miao C, Hsu K, Gao X (2017) Evaluation of CMIP5 model precipitation using PERSIANN-CDR. J Hydrometeorol. https://doi. org/10.1175/JHM-D-16-0201.1

Nikiema PM, Sylla MB, Ogunjobi K, Kebe I, Gibba P, Giorgi F (2017) Multi-model CMIP5 and CORDEX simulations of historical summer temperature and precipitation variabilities over West Africa. Int J Climatol. https://doi.org/10.1002/joc.4856

Park S, Shin J (2019) Snu sam0-unicon model output prepared for cmip6 cmip historical.

Pendergrass AG, Hartmann DL (2014) Changes in the distribution of rain frequency and intensity in response to global warming. J Clim. https://doi.org/10.1175/JCLI-D-14-00183.1

Smith AB, Katz RW (2013) US billion-dollar weather and climate disasters: Data sources, trends, accuracy and biases. Nat Hazards. https://doi.org/10.1007/s11069-013-0566-5

Swart NC, Cole JNS, Kharin VV, Lazare M, Scinocca JF, Gillett NP, Anstey J, Arora V, Christian JR, Hanna S, Jiao Y, Lee WG, Majaess F, Saenko OA, Seiler C, Seinen C, Shao A, Sigmond M, Solheim L, Winter B (2019) The Canadian earth system model version 5 (CanESM5.0.3). Geosci Model Dev. https://doi. org/10.5194/gmd-12-4823-2019

Sylla MB, Giorgi F, Coppola E, Mariotti L (2013) Uncertainties in daily rainfall over Africa: Assessment of gridded observation products and evaluation of a regional climate model simulation. Int J Climatol 33:1805-1817. https://doi.org/10.1002/joc.3551

Tank, A. K., Zwiers, F. W., \& Zhang, X. (2009). Guidelines on Analysis of extremes in a changing climate in support of informed decisions for adaptation, WCDMP-No. 72. In Climate Data and Monitoring.

Tatebe H, Ogura T, Nitta T, Komuro Y, Ogochi K, Takemura T, Sudo K, Sekiguchi M, Abe M, Saito F, Chikira M, Watanabe S, Mori M, Hirota N, Kawatani Y, Mochizuki T, Yoshimura K, Takata K,
O'Ishi R, Kimoto M (2019) Description and basic evaluation of simulated mean state, internal variability, and climate sensitivity in MIROC6. Geoscientific Model Development. https://doi. org/10.5194/gmd-12-2727-2019

Taylor KE, Stouffer RJ, Meehl GA (2012) An overview of CMIP5 and the experiment design. Bull Am Meteor Soc. https://doi. org/10.1175/BAMS-D-11-00094.1

Tegen I, Neubauer D, Ferrachat S, Drian SL, Bey I, Schutgens N, Stier P, Watson-Parris D, Stanelle T, Schmidt H, Rast S, Kokkola H, Schultz M, Schroeder S, Daskalakis N, Barthel S, Heinold B, Lohmann U (2019) The global aerosol-climate model ECHAM6. 3-HAM2. 3-Part 1: aerosol evaluation. Geosci Model Dev. https ://doi.org/10.3929/ethz-b-000341297

Torma C, Coppola E, Giorgi F, Bartholy J, Pongrácz R (2011) Validation of a high-resolution version of the regional climate model RegCM3 over the Carpathian basin. J Hydrometeorol. https://doi. org/10.1175/2010JHM1234.1

Trenberth KE (2011) Changes in precipitation with climate change. Clim Res. https://doi.org/10.3354/cr00953

Trenberth KE, Dai A, Van Der Schrier G, Jones PD, Barichivich J, Briffa KR, Sheffield J (2014) Global warming and changes in drought. Nat Clim Change. https://doi.org/10.1038/nclimate2067

Volodin EM, Mortikov EV, Kostrykin SV, Galin VY, Lykossov VN, Gritsun AS, Diansky NA, Gusev AV, Iakovlev NG, Shestakova AA, Emelina SV (2018) Simulation of the modern climate using the INM-CM48 climate model. Russ J Numer Anal Math Model. https://doi.org/10.1515/rnam-2018-0032

Wu T, Lu Y, Fang Y, Xin X, Li L, Li W, Jie W, Zhang J, Liu Y, Zhang L, Zhang F, Zhang Y, Wu F, Li J, Chu M, Wang Z, Shi X, Liu X, Wei M, Liu X (2019) The Beijing climate center climate system model (BCC-CSM): the main progress from CMIP5 to CMIP6. Geosci Model Dev. https://doi.org/10.5194/gmd-12-1573-2019

Yukimoto S, Kawai H, Koshiro T, Oshima N, Yoshida K, Urakawa S, Tsujino H, Deushi M, Tanaka T, Hosaka M, Yabu S, Yoshimura H, Shindo E, Mizuta R, Obata A, Adachi Y, Ishii M (2019) The meteorological research institute Earth system model version 2.0, MRI-ESM2.0: description and basic evaluation of the physical component. J Meteorol Soc Jpn. https://doi.org/10.2151/ jmsj.2019-051

Zhang X, Alexander L, Hegerl GC, Jones P, Tank AK, Peterson TC, Trewin B, Zwiers FW (2011) Indices for monitoring changes in extremes based on daily temperature and precipitation data. Wiley Interdisciplinary Reviews. Clim Change. https://doi.org/10.1002/ wcc. 147

Zhang J, Wu T, Shi X, Zhang F, Li J, Chu M, Liu Q, Yan J, Ma Q, Wei M (2019) BCC BCC-ESM1 model output prepared for CMIP6 AerChemMIP. Earth Syst Grid Fed. https://doi.org/10.22033/ ESGF/CMIP6.1733 